\title{
The Role of Tropical-Extratropical Interaction and Synoptic Variability in Maintaining the South Pacific Convergence Zone in CMIP5 Models
}

\author{
MATTHEW J. NiZNIK AND BENJAMIN R. LINTNER \\ Department of Environmental Sciences, Rutgers, The State University of New Jersey, New Brunswick, New Jersey
}

\section{ADRIAN J. MATTHEWS}

Centre for Ocean and Atmospheric Sciences, School of Environmental Sciences and School of Mathematics, University of East Anglia, Norwich, United Kingdom

\section{MATTHEW J. WIDLANSKY}

International Pacific Research Center, University of Hawai' $i$ at Mānoa, Honolulu, Hawaii

(Manuscript received 25 July 2014, in final form 23 January 2015)

\begin{abstract}
The South Pacific convergence zone (SPCZ) is simulated as too zonal a feature in the current generation of climate models, including those in phase 5 of the Coupled Model Intercomparison Project (CMIP5). This zonal bias induces errors in tropical convective heating, with subsequent effects on global circulation. The SPCZ structure, particularly in the subtropics, is governed by the tropical-extratropical interaction between transient synoptic systems and the mean background state. In this study, analysis of synoptic variability in the simulated subtropical SPCZ reveals that the basic mechanism of tropical-extratropical interaction is generally well simulated, with storms approaching the SPCZ along comparable trajectories to observations. However, there is a broad spread in mean precipitation and its variability across the CMIP5 ensemble. Intermodel spread appears to relate to a biased background state in which the synoptic waves propagate. In particular, the region of mean negative zonal stretching deformation or "storm graveyard" in the upper troposphere is displaced in CMIP5 models to the northeast of its position in reanalysis data, albeit with pronounced $\left(\approx 25^{\circ}\right)$ intermodel longitudinal spread. Precipitation along the eastern edge of the SPCZ shifts in accordance with a storm graveyard shift, and in general models with stronger storm graveyards show higher precipitation variability. Building on prior SPCZ research, it is suggested that SPCZs simulated by CMIP5 models are not simply too zonal; rather, in models the subtropical SPCZ manifests a diagonal tilt similar to observations while SST biases force an overly zonal tropical SPCZ, resulting in a more discontinuous SPCZ than observed.
\end{abstract}

\section{Introduction}

The South Pacific convergence zone (SPCZ) is the largest area of climatologically contiguous convective precipitation spanning beyond the tropics. It consists of a zonal band of precipitation in the equatorial western Pacific and a diagonal band of storminess that extends southeastward into the Southern Hemisphere midlatitudes. The convection is distinct from the intertropical

Corresponding author address: Matthew J. Niznik, Department of Environmental Sciences, Rutgers, The State University of New Jersey, 14 College Farm Road, New Brunswick, NJ 08901-8551. E-mail: matthew.niznik@rutgers.edu convergence zone (ITCZ) that lies north of the equator over the Pacific (along $8^{\circ} \mathrm{N}$; Figs. 1 and 2a,b). The SPCZ is responsible for a large fraction of the precipitation occurring across the South Pacific, particularly in austral summer [December-February (DJF)], while intense convective heating in the SPCZ generates and modifies Rossby waves, giving the SPCZ a global influence (Brown et al. 2011; Matthews 2012). From a societal perspective, the inhabitants of South Pacific island nations are dependent on SPCZ rainfall; deviations from a typical year can result in substantial drought or flooding throughout the region (Murphy et al. 2014). Additionally, the SPCZ is a region of tropical cyclogenesis with large interannual variability in the locations of cyclogenesis and numbers of 


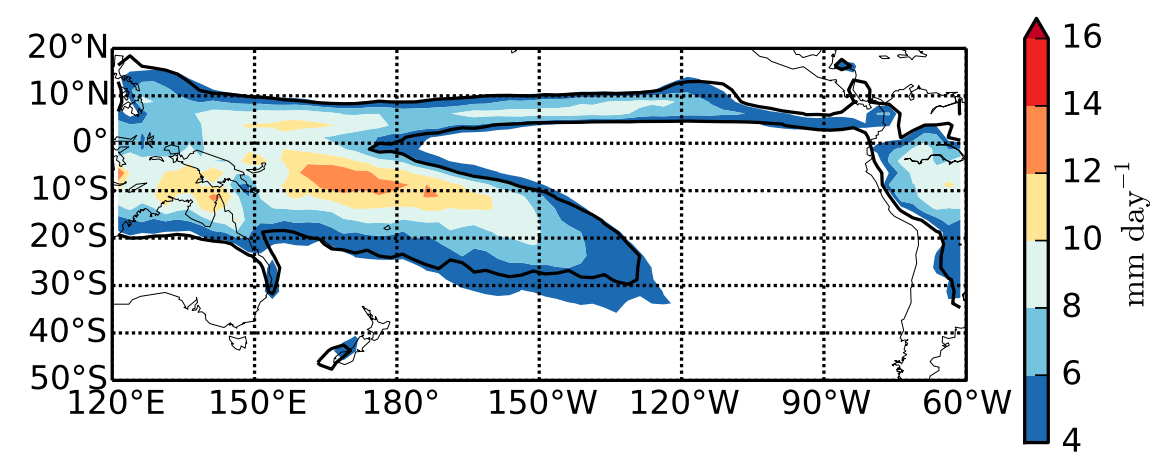

FIG. 1. Climatological DJF precipitation (shading, $\mathrm{mm} \mathrm{day}^{-1}$ ) over the Pacific for the CPC Merged Analysis of Precipitation (CMAP), with the Tropical Rainfall Measuring Mission (TRMM) $4 \mathrm{~mm} \mathrm{day}^{-1}$ contour (in black) included for reference.

cyclones (Vincent et al. 2011), as well as extreme sea level variability (Widlansky et al. 2014). Given the inherent societal impacts associated with the SPCZ and its variability, there is strong interest in better understanding the SPCZ in both present-day climate [e.g., Southwest Pacific Ocean Circulation and Climate Experiment (SPICE); see Ganachaud et al. 2007, 2014] and projected future climate [e.g., the Pacific-Australia Climate

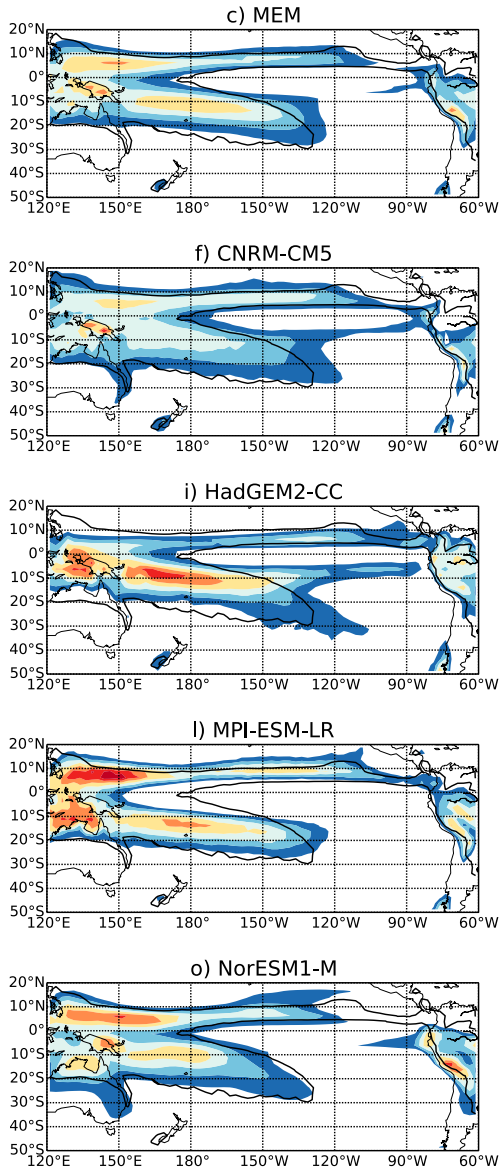

FIG. 2. Climatological DJF precipitation (shading, $\mathrm{mm} \mathrm{day}^{-1}$ ) over the Pacific for the (a) TRMM estimated dataset, (b) Climate Forecast System Reanalysis (CFSR), (c) phase 5 of the Coupled Model Intercomparison Project (CMIP5) coupled model ensemble mean (MEM), and (d)-(o) individual CMIP5 coupled model means. The thick black line in all panels is the TRMM 4 mm day ${ }^{-1}$ contour, for reference. 
Change Science and Adaptation Planning (PACCSAP) program; see Australian Bureau of Meteorology and CSIRO 2011a,b].

Simulation of the SPCZ remains problematic in global climate models (GCMs) (Brown et al. 2013; Widlansky et al. 2013). Identification and attribution of these biases in the climatological mean sense in members of phase 3 of the Coupled Model Intercomparison Project (CMIP3; Meehl et al. 2007) and phase 5 (CMIP5; Taylor et al. 2012) is extensive (e.g., Brown et al. 2011, 2013; Widlansky et al. 2013). Many GCMs simulate an SPCZ with an overly zonal orientation; applying a linear fit to precipitation maxima across the South Pacific to two observational datasets, Brown et al. (2013) noted slopes of -0.25 and -0.28 degrees latitude per degree longitude, whereas the CMIP5 multimodel mean slope is only -0.09 degrees latitude per degree longitude (Fig. 2c). Furthermore, none of the models examined (Figs. $2 \mathrm{~d}-\mathrm{o}$ ) has a slope steeper than the observations. In some cases, this zonal orientation makes the SPCZ indistinguishable from a second ITCZ in the Southern Hemisphere (i.e., the so-called double ITCZ bias; Zhang 2001; Lin 2007; de Szoeke and Xie 2008; Bellucci et al. 2010; Brown et al. 2011, 2013), although the bias can also be exhibited via an ITCZ that migrates across the equator (thus appearing as two ITCZs in an annual or climatological mean) or anomalous convection confined to the eastern Pacific. These biases in essence connect an otherwise separate SPCZ to a spurious ITCZ (de Szoeke and Xie 2008; Bellucci et al. 2010; Brown et al. 2011). Both the double ITCZ bias and the zonal SPCZ bias are tied to errors in South Pacific sea surface temperatures (SSTs) simulated in coupled models; cooler than observed SSTs along the equator, termed the Pacific "cold tongue," play a key role in setting up these errors in precipitation simulation (Ashfaq et al. 2011; Widlansky et al. 2013; Vannière et al. 2014). Atmospheric models forced with observed SSTs in lieu of a coupled ocean show significant reductions in mean-state biases of precipitation (Widlansky et al. 2013).

Model errors in the variability of the SPCZ have also been diagnosed. On interannual time scales, the SPCZ shifts in accordance with the phase of El Niño-Southern Oscillation (ENSO) and its accompanying SST perturbations, as precipitation migrates toward the northeast during El Niño and toward the southwest during La Niña (e.g., Trenberth 1976; Folland et al. 2002; Vincent et al. 2011). While not all CMIP3 models show skill in simulating a shift in SPCZ position related to the phase of ENSO, all but one CMIP5 model produced a correlation between SPCZ latitude and Niño-3.4 SST significant at the $95 \%$ level (Brown et al. 2011, 2013). Moving beyond this simple linear relationship, Cai et al. (2012) identified episodes in which the SPCZ effectively collapses onto the equator-so-called zonal SPCZ events-during El Niños with strong eastern Pacific warming (Borlace et al. 2014). Examining a suite of CMIP3 and CMIP5 models, Cai et al. (2012) determined that 9 of 17 CMIP3 models and 12 of 20 CMIP5 models are incapable of capturing zonal SPCZ events, suggesting common model deficiencies on interannual time scales. On intraseasonal time scales, the SPCZ interacts with the Madden-Julian oscillation (MJO) (Matthews et al. 1996; Matthews 2012). While CMIP5 models simulate better MJO variance peaks than CMIP3 models, MJO propagation remains too slow in most models (Lin et al. 2006; Hung et al. 2013). It is likely that these biases will affect SPCZ variability on $\mathrm{MJO}$ time scales, although to our knowledge no study has yet explicitly examined MJO-SPCZ interactions in CMIP5 models.

Ultimately, convection and precipitation are controlled by synoptic variability and tropical-extratropical interaction in the diagonal part of the SPCZ (Streten 1973; Vincent 1994; Kiladis and Weickmann 1997). Synoptic-scale waves travel along the subtropical jet over the southern Indian Ocean and south of Australia. Through Rossby wave dynamics, refraction occurs, redirecting the synoptic waves equatorward into the westerly duct in the upper troposphere over the equatorial Pacific. Precipitating deep convection is then triggered in the destabilized rising air ahead of the cyclonic vorticity anomalies in these wave trains, consistent with quasigeostrophic dynamics. The changes in SPCZ precipitation associated with the MJO and ENSO are largely due to changes in the frequency and propagation paths of these synoptic waves (Matthews 2012) that are embedded in the slowly varying basic state of the specific MJO or ENSO event.

Errors in SPCZ simulation in GCMs on synoptic time scales are, to this point, comparatively unknown. Niznik and Lintner (2013) showed that synoptic time scale changes to low-level inflow east of the SPCZ in coupled GCMs are associated with spatial shifts in precipitation consistent with observations, albeit with considerable intermodel spread in the spatial distributions of these shifts. These results implicate potential connections between low-level inflow variability and the frequency with which synoptic disturbances interact with the SPCZ. Further motivation in understanding model biases on synoptic time scales comes from recent theoretical advances linking the orientation of the SPCZ to the slowing of eastward-propagating synoptic disturbances (Widlansky et al. 2011) within the aptly named "storm graveyard" (Trenberth 1976). The storm graveyard is a region where upper-level negative zonal stretching deformation (ZSD; $\partial \bar{U} / \partial x)$ is negative; thus the group 
TABLE 1. CMIP5 models used in this paper. The latitude and longitude columns (Lat. and Lon.at., respectively) list the resolution of the model output available from PCMDI's CMIP5 database. Further information can be found online at http://cmip-pcmdi.llnl.gov/cmip5/ docs/CMIP5_modeling_groups.pdf.

\begin{tabular}{lcc}
\hline \hline \multicolumn{1}{c}{ Modeling group } & CMIP5 model name & Lat. $\left(^{\circ}\right)$ \\
\hline National Center for Atmospheric Research (NCAR) & 0.94 \\
Centro Euro-Mediterraneo per I Cambiamenti Climatici (CMCC) & CCSM4 (r6) & 1.25 \\
Centre National de Recherches Meteorologiques / Centre Europeen & CMCC-CM & 0.75 \\
$\quad$ de Recherche et Formation Avancees en Calcul Scientifique & CNRM-CM5 & 1.41 \\
Commonwealth Scientific and Industrial Research Organization in & CSIRO-Mk3.6.0 & 1.41 \\
$\quad$ collaboration with Queensland Climate Change Centre of Excellence & & 1.88 \\
NOAA Geophysical Fluid Dynamics Laboratory & GFDL-CM3 & 2.00 \\
Met Office Hadley Centre & HadGEM2-CC* & 1.25 \\
Institute for Numerical Mathematics & INM-CM4 & 1.50 \\
Institute Pierre-Simon Laplace (IPSL) & IPSL-CM5A-MR & 1.50 \\
Max Planck Institute for Meteorology & MPI-ESM-LR & 2.00 \\
& MPI-ESM-MR & 2.50 \\
Meteorological Research Institute & MRI-CGCM3 & 1.88 \\
Norwegian Climate Centre & NorESM1-M & 1.88 \\
\hline
\end{tabular}

* HadGEM2-CC is called HadGEM2-A in the AMIP output. For consistency, we will refer to the model as HadGEM2-CC for both the historical and AMIP experiments.

speed of disturbances decreases. Here, wave energy density increases (Widlansky et al. 2011), which in the presence of sufficiently warm SSTs (Matthews 2012; van der Wiel et al. 2015) and conditional instability in the vicinity of the SPCZ triggers deep convection. Matthews (2012) and van der Wiel et al. (2015) further expand upon this idea, positing that the climatological SPCZ is the sum of "pulses" of energy in the region associated with synoptic disturbances.

These recent advances in SPCZ theory suggest that the synoptic time scales may be particularly important, yet there has been no comprehensive assessment of the fidelity with which individual GCMs capture the interactions mentioned above. Here, we apply several metrics to quantify the extent to which CMIP5 models simulate key interactions on synoptic time scales, particularly between synoptic disturbances and the SPCZ. Section 2 outlines the data and analysis methodology used in this paper. Section 3 provides an overview of climatological precipitation biases in the models analyzed and examines model variability on synoptic time scales. Section 4 outlines model biases in the intensity and position of the storm graveyard. Section 5 shows the results of composite analyses constructed to examine SPCZ-storm interactions. Finally, conclusions and remaining questions are given in section 6 .

\section{Data and methodology}

Twelve CMIP5 models were examined in this work (Table 1); all had output from the following four variables available at daily resolution in both the CMIP5 "historical" and "AMIP" (Atmospheric Model
Intercomparison Project) experiments: zonal wind, meridional wind, specific humidity, and precipitation. With the exception of CCSM4, the models also had top-ofatmosphere (TOA) outgoing longwave radiation (OLR) output available at the same temporal resolution in both experiments. The two experiments differ principally in ocean and sea ice; the historical experiment (1850-2005) is a full ocean-atmosphere coupled integration (Taylor et al. 2012), whereas the AMIP experiment (1979-2008) is an atmosphere-only configuration forced by observed SST and sea ice. For clarity, the CMIP5 model output from the historical and AMIP experiments will be referred to as coming from coupled models and atmosphere-only, respectively. Both model sets include observed anthropogenic and natural radiative forcing in their respective time spans.

All available output was regridded to a common $2.5^{\circ} \times 2.5^{\circ}$ latitude/longitude grid via area averaging. For those analyses requiring annual data, all available days in each experiment, 46 years for coupled (19602005) and 30 years for atmosphere-only (1979-2008), were used to ensure a representative distribution of variability in each model and experiment is captured. (For completeness, we also repeated select analyses using a shorter time period for coupled models matching the atmosphere-only time period length, although the results were qualitatively similar and are not shown here.) For those analyses requiring DJF data, all days in those months were included with the exception of days from the first January, first February, and last December of the time span since these are not part of a fully contiguous DJF; thus, DJF analyses contain one less "year" (45 for coupled, 29 for atmosphere-only). 
TABLE 2. DJF climatological precipitation $\left(\mathrm{mm} \mathrm{day}^{-1}\right)$ over the subtropical SPCZ region $\left(20^{\circ}-35^{\circ} \mathrm{S}, 135^{\circ}-165^{\circ} \mathrm{W}\right)$. Models with mean precipitation greater than 1 standard deviation from the median of models are shown in bold.

\begin{tabular}{lccc}
\hline \multicolumn{1}{c}{ Dataset } & & & \\
\hline TRMM & 4.11 & - & - \\
CMAP & 5.00 & - & - \\
CFSR & 5.27 & - & - \\
& Coupled & Atmosphere-only & Difference \\
& models & models & \\
CCSM4 & 3.74 & 3.43 & -0.31 \\
CMCC-CM & $\mathbf{3 . 2 8}$ & 4.72 & 1.44 \\
CNRM-CM5 & 3.79 & 4.37 & 0.58 \\
CSIRO-Mk3.6.0 & 3.68 & 3.98 & 0.30 \\
GFDL-CM3 & 3.90 & 3.99 & 0.09 \\
HadGEM2-CC & $\mathbf{4 . 4 7}$ & $\mathbf{4 . 9 0}$ & 0.43 \\
INM-CM4 & 4.30 & $\mathbf{5 . 2 1}$ & $\mathbf{0 . 9 1}$ \\
IPSL-CM5A-MR & 3.85 & 4.21 & 0.36 \\
MPI-ESM-LR & 3.98 & 3.97 & -0.01 \\
MPI-ESM-MR & 3.93 & 4.03 & 0.10 \\
MRI-CGCM3 & $\mathbf{2 . 5 5}$ & $\mathbf{5 . 9 8}$ & $\mathbf{3 . 4 3}$ \\
NorESM1-M & 3.45 & 3.96 & 0.45 \\
Median of models & 3.82 & 4.12 & 0.30 \\
St. dev. of models & 0.50 & 0.70 & 0.20 \\
\hline
\end{tabular}

As a basis for comparison in the relatively data-sparse South Pacific, the National Centers for Environmental Prediction (NCEP) Climate Forecast System Reanalysis (CFSR; Saha et al. 2010) is used in all analyses during the 32-yr period spanning 1979-2010 (variables examined in the CMIP5 models are also available for CFSR during this period). Niznik and Lintner (2013) showed that CFSR captures the climatological position of the SPCZ well (cf. Fig. 2). Precipitation estimates from the Tropical Rainfall Measuring Mission (TRMM) 3B42 dataset (Kummerow et al. 2000) are used to develop estimated precipitation intensity histograms, with the caveat that the record used is comparatively short (December 1998February 2013). Additionally, data from the Climate Prediction Center (CPC) Merged Analysis of Precipitation (CMAP; Xie and Arkin 1997) spanning December 1979-February 2011 is used to supplement TRMM estimates for climatological precipitation values in the subtropical $\left(20^{\circ}-35^{\circ} \mathrm{S}, 135^{\circ}-165^{\circ} \mathrm{W}\right)$ portion of the SPCZ. We note that precipitation (and specific humidity) values across the South Pacific remain somewhat uncertain; while these products (TRMM, CMAP, CFSR) do have some notable disagreement (e.g., $1 \mathrm{~mm}$ day $^{-1}$ difference in precipitation in the subtropical SPCZ between TRMM and CFSR; see Table 2), both the range of values among these data sources and also their qualitative aspects are still useful for comparison to model output.

As a measure of the spread of convective activity, precipitation standard deviations are calculated both for the entire record as well as on synoptic time scales, defined here as 14 days or less. To isolate synoptic precipitation variability, a fast Fourier transform (FFT) was calculated and a time series was then reconstructed from only those signals with periods of 14 days or fewer; the synoptic precipitation variability corresponds to the standard deviation of this time series. Additionally, principal uncertainty patterns (PUPs) are generated by performing empirical orthogonal function analysis replacing the time dimension with $N$ model realizations of a given field (see Anderson et al. 2015); in this way, key intermodel differences between simulated variables can be isolated and quantified. Here, PUPs are calculated for both total and synoptic precipitation variability to aid in grouping models based on precipitation variability magnitude. Precipitation histograms at the daily time scale in DJF are generated in the subtropical region of the SPCZ as well as for TRMM and model output. All precipitation counts from grid cells within an individual region are used to construct the histograms with bin spacings of $2.5 \mathrm{~mm} \mathrm{day}^{-1}$ (with three exceptions: the first bin of each histogram spans $0-0.5 \mathrm{~mm} \mathrm{day}^{-1}$, thus grouping zero and trace precipitation together, the second bin spans $0.5-2.5 \mathrm{~mm} \mathrm{day}^{-1}$, and the final bin captures all events greater than $100 \mathrm{mmday}^{-1}$ ). This methodology was repeated using only those grid cells in each region that have climatological precipitation values greater than $4 \mathrm{~mm} \mathrm{day}^{-1}$, although the results are robust to this change. Biases with respect to TRMM for each model are obtained for the daily time scale by calculating the difference between each model's counts and the TRMM counts and then normalizing by the TRMM counts in each bin (e.g., 0.3 represents $30 \%$ higher counts on average in a particular model, while -0.3 represents $30 \%$ lower counts).

The time scale dependence of the SPCZ variability is diagnosed from power spectra calculations. Daily values of TOA OLR from interpolated observed values in the period 1979-2012 (see Liebmann and Smith 1996), CFSR, and model output in a $5^{\circ} \times 5^{\circ}$ subset $\left(25^{\circ}-30^{\circ} \mathrm{S}\right.$, $147.5^{\circ}-152.5^{\circ} \mathrm{W}$ ) of the subtropical SPCZ were analyzed, following the precedent of spectral analyses performed by Widlansky et al. (2011) and Matthews (2012). While the observational dataset should not be used for direct quantitative comparison with the model output because observations cannot truly capture total TOA OLR, the means and variances of both products are qualitatively similar (G. Kiladis 2014, personal communication). For each data source, the time series of OLR at each grid cell in the subtropical SPCZ was converted to anomalous OLR by subtracting the day-specific climatological OLR value obtained by combining the mean OLR and the first three harmonics of the unsmoothed annual cycle in observations (i.e., anomalies on 
1 January 1980 were calculated by subtracting an idealized climatological value of OLR specific to that day of year from the raw value). OLR values were then averaged spatially, resulting in one time series for the subtropical SPCZ, and a power spectrum was then calculated (frequency range $1 / n$ through 0.5 with interval spacing $1 / n$, where $n$ is the total number of days in the time series). The power spectra was smoothed by a 181-point running mean (representing approximately $2 \%$ of all points for the coupled model data and $3 \%$ of all points for CFSR and atmosphere-only models) to remove noise due to a high density of frequencies on short time scales; e.g., $33 \%$ of the calculated points are between a period of 2 and 3 days. In addition, a theoretical background red-noise spectrum was calculated by assuming that the time series reflects a firstorder Markov process and using the lag- 1 autocorrelation coefficient, with $95 \%$ confidence intervals obtained from a chi-squared test assuming $362(2 \times 181)$ degrees of freedom. The procedure for precipitation power spectra calculations is identical. To normalize the spectra for comparison, all power spectra are multiplied by the number of years in the source time series and then divided by the smallest number of years in any given comparison ( 32 for coupled model TOA OLR, 30 years for atmosphere-only TOA OLR, and 15 years for coupled and atmosphere-only precipitation).

For the storm graveyard calculations, the zonal derivative of zonal wind $(\partial \bar{U} / \partial x)$, that is, the zonal stretching deformation ZSD, was calculated via a simple centered difference scheme for CFSR and model output. Although Widlansky et al. (2011) analyzed data at the 200-hPa level, the 250-hPa level is chosen here to match the standard archived CMIP5 model output. Comparison of the storm graveyard shape and intensity at these two levels in the CFSR (e.g., Saha et al. 2010) shows minimal difference. For intermodel comparison, as well as comparison with CFSR, the magnitude and location of the minimum in ZSD in both the reanalysis as well as the CMIP5 models is calculated in the region $40^{\circ}-15^{\circ} \mathrm{S}, 180^{\circ}-110^{\circ} \mathrm{W}$, chosen primarily to capture the storm graveyard while excluding an area of strong negative ZSD located in the eastern equatorial Pacific.

To diagnose the synoptic characteristics of the SPCZ variability, composite analyses were performed based on an index created by averaging daily $250-\mathrm{hPa}$ vorticity anomalies from monthly means over the region centered on CFSR's climatological ZSD minimum $\left(30^{\circ}-27.5^{\circ} \mathrm{S}\right.$, $\left.140^{\circ}-127.5^{\circ} \mathrm{W}\right)$. All days with a vorticity index less than 1.5 standard deviations below the mean (i.e., strongly negative) cyclonic vorticity that are also the minima in centered five-day periods are included in the composite. Additionally, a lead-lag analysis is performed by considering composites for the 6-day period before and after the composite days. Note that separate compositing indices were created for the CFSR dataset and for each of the model datasets. To check the robustness of the methodology, an alternative index was created by averaging the vorticity anomaly over a similarly sized region centered on the climatological ZSD minimum for each model rather than using the same CFSR-defined region for each model; the results were qualitatively similar.

The mean speed and linear trajectory of each storm contributing to the composites were also calculated, using a simple vorticity backtracking algorithm. For each event in the composite analysis, the algorithm searches a circle with a radius of 5 grid cells and centered on the day 0 vorticity anomaly (i.e., between due west and due south of the anomaly) for a negative vorticity anomaly on the previous day (day - 1). If an anomaly is found, the same process is repeated, but moving the starting location to the anomaly at day -1 in order to find the anomaly on day -2 . If no negative anomaly is found on day -1 or day -2 , that particular anomaly is excluded from the trajectory plots. Additionally, all vorticity anomalies that do not propagate toward the SPCZ between due east and due north from day -2 through day 0 are excluded from the analysis. The chosen range of approach trajectories is consistent with current SPCZ-storm interaction theory; upper-level vorticity anomalies approach the SPCZ along the Southern Hemisphere subtropical jet and are steered equatorward near the storm graveyard (Widlansky et al. 2011; Matthews 2012). The excluded approach angles could be associated with equatorial waves (especially those propagating toward the west) or the algorithm erroneously associating unrelated convection with the day 0 event. Using this algorithm, a mean speed and trajectory is calculated as the trajectory from the mean position of anomalies on day -2 to the mean position of all anomalies on day 0 .

\section{Synoptic-scale variability biases}

\section{a. Model precipitation biases}

Before presenting the synoptic analysis, we first summarize the climatological model biases across the South Pacific. Precipitation climatologies across the South Pacific in both coupled and atmosphere-only models are depicted in Figs. 2 and 3, respectively, for the 12 models examined in this work in addition to TRMM, CFSR, and the model ensemble mean (MEM); for comparison, the CMAP precipitation climatology is shown in Fig. 1. Coupled model biases in the region include a poleward displacement of and enhanced convection in the Northern Hemisphere ITCZ, unrealistically intense precipitation 

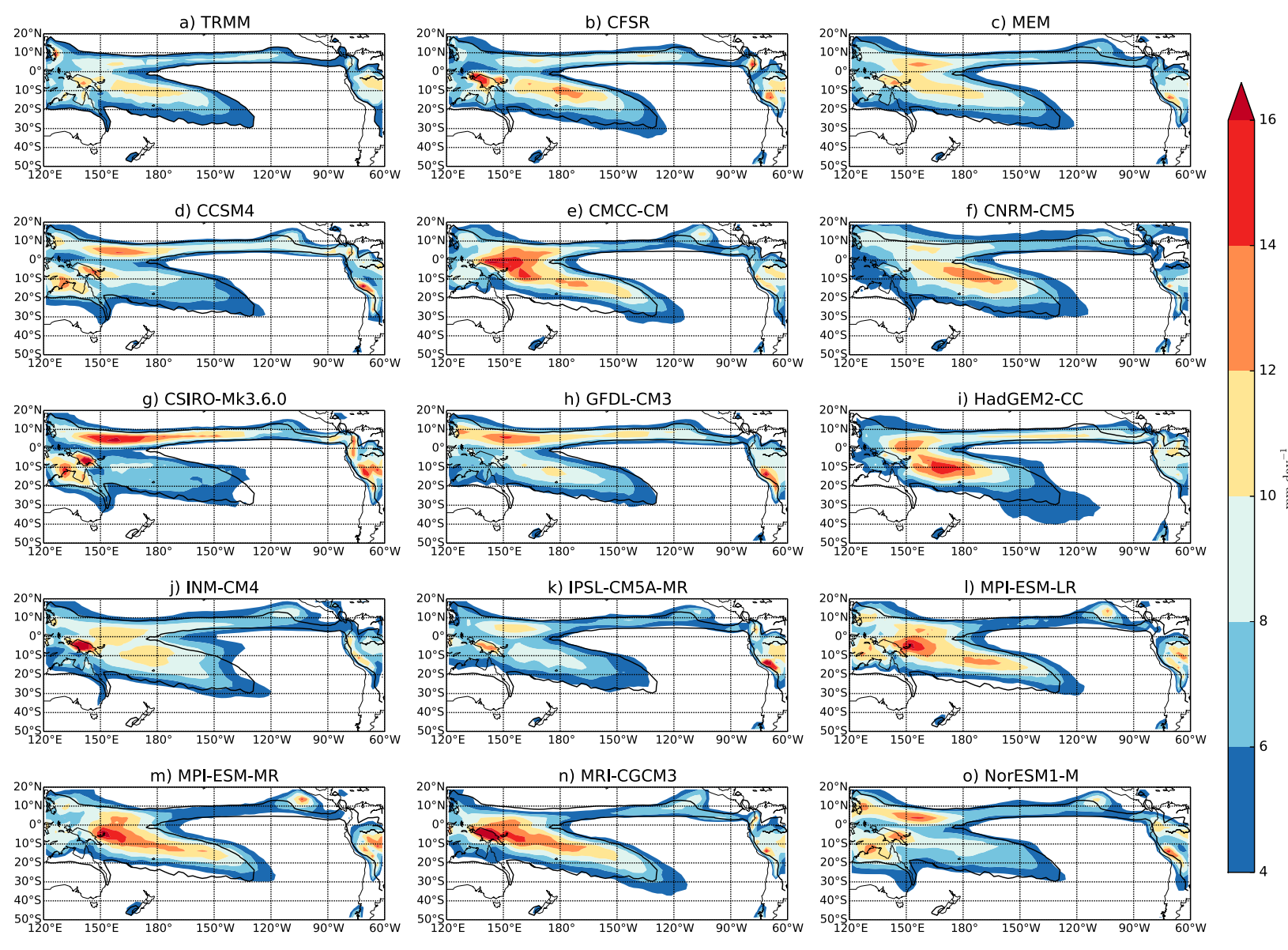

FIG. 3. As Fig. 2, but for the (c) model ensemble mean and (d)-(o) individual means of the atmosphere-only models.

along $10^{\circ} \mathrm{S}$ in the eastern Pacific, and a dry bias in the western equatorial Pacific (150-180 $\left.{ }^{\circ} \mathrm{E}\right)$ associated with the cold tongue bias. Stronger than observed precipitation in the southeastern Pacific, as shown in the MEM, stems from a combination of models simulating an SPCZ that extends farther east as well as the generation of a spurious Southern Hemisphere ITCZ (de Szoeke and Xie 2008; Bellucci et al. 2010; Brown et al. 2011). Individual models do not necessarily exhibit both of these biases; for example, CMCC-CM shows a bias solely due to the eastward-extended SPCZ, IPSLCM5A-MR shows a bias solely due to the Southern Hemisphere ITCZ, and MRI-CGCM3 shows evidence of both. Additionally, the dry bias in the western equatorial Pacific manifests considerable spread. Whereas CSIRO-Mk3.6.0 and MPI-ESM-LR/MR both have a strong dry bias, CNRM-CM5 has notable precipitation on the equator in the region $150^{\circ} \mathrm{E}-180^{\circ}$. Averaging precipitation over the subtropical SPCZ (Table 2) reveals that despite an approximate $1 \mathrm{~mm} \mathrm{day}^{-1}$ difference between TRMM and both of CFSR and CMAP, many individual coupled models, in addition to the
MEM, simulate lower values than both estimates and reanalysis.

In the climatological sense, forcing a model with realistic SSTs in the region alleviates most precipitation biases (see the atmosphere-only models in Fig. 3 and mean precipitation values in Table 2), as suggested in previous studies (e.g., Widlansky et al. 2013). However, there remains a tendency for models to simulate an SPCZ farther northeast than observed. As a first step in determining how well the models simulate synopticscale variability, and how errors in synoptic-scale simulation may impact biases in the SPCZ, we show the standard deviation of precipitation across the South Pacific in atmosphere-only models both for all time scales (Fig. 4) and for synoptic time scales only (14-day high-pass filtered; Fig. 5). It is immediately apparent that the models differ considerably in the magnitude of variability within the $4 \mathrm{~mm} \mathrm{day}^{-1}$ contour of the SPCZ. Additionally, those models that tend to simulate smaller precipitation standard deviations overall also show substantially less precipitation variability on the northern margin of the SPCZ compared to the southern edge. 

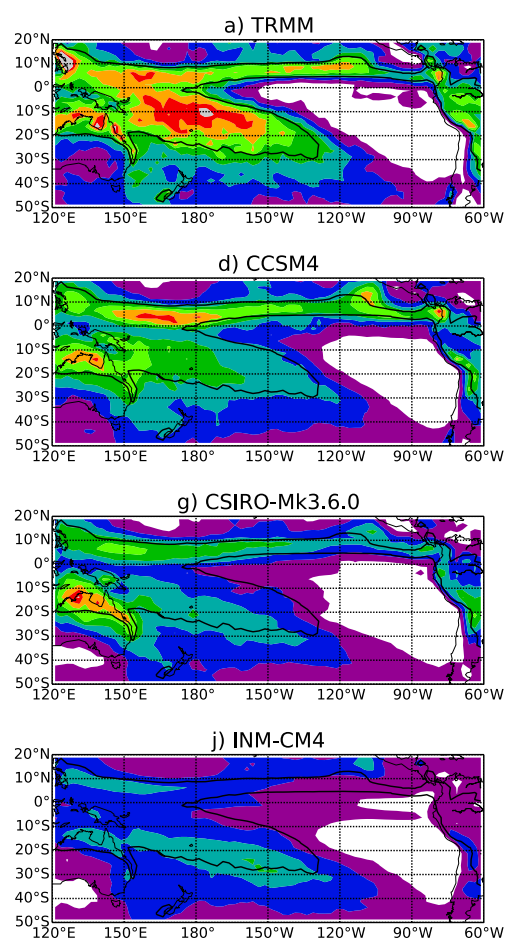

m) MPI-ESM-MR

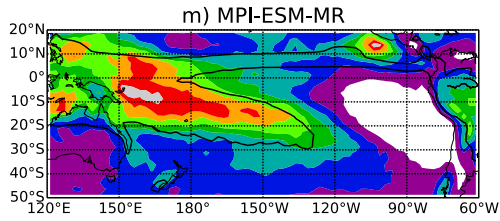

b) CFSR

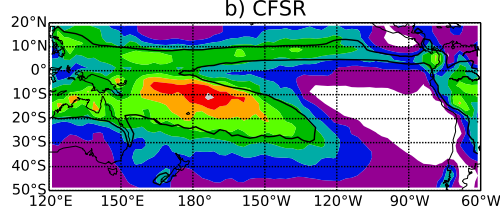

e) CMCC-CM

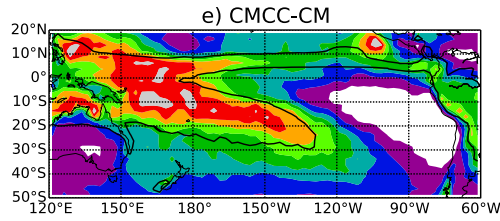

h) GFDL-CM3

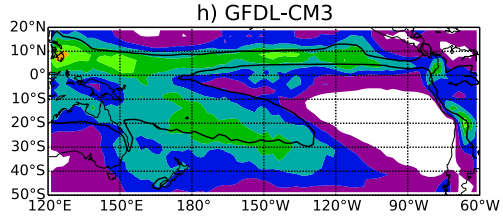

k) IPSL-CM5A-MR

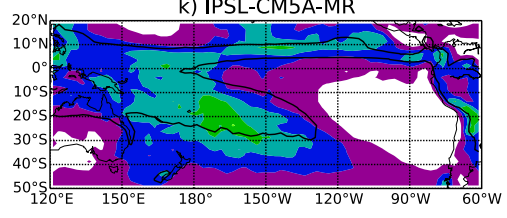

n) MRI-CGCM3

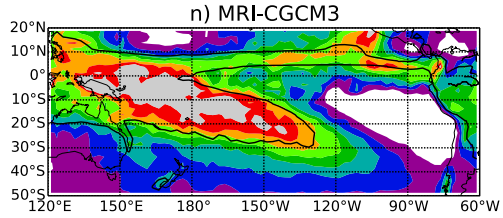

c) MEM

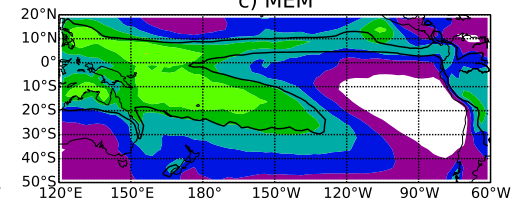

f) CNRM-CM5

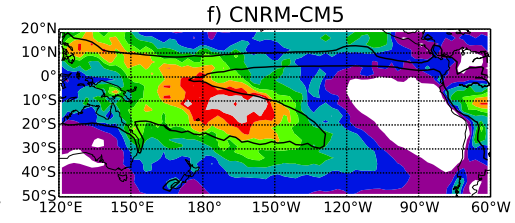

i) HadGEM2-CC

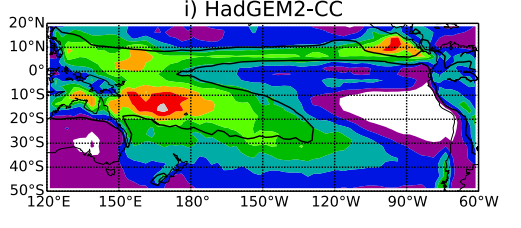

1) MPI-ESM-LR

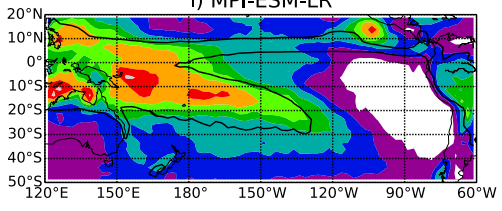

o) NorESM1-M

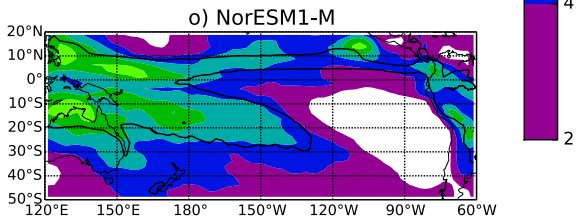

FIG. 4. Climatological DJF precipitation standard deviation (shading, $\mathrm{mm}^{-1} \mathrm{yy}^{-1}$ ) over the Pacific for the (a) TRMM estimated dataset, (b) CFSR, (c) CMIP5 atmosphere-only model ensemble mean (MEM), and (d)-(o) individual CMIP5 atmosphere-only model means. The thick black line in all panels is the TRMM $4 \mathrm{~mm}$ day $^{-1}$ climatological precipitation contour, for reference.

These magnitudes are consistent with those obtained using the coupled models (not shown); regardless of where the SPCZ is located in coupled models, precipitation variability is enhanced relative to surrounding regions but with sizeable spread across the ensemble. However, fewer coupled models show a low bias on the northern edge of the SPCZ.

For a more rigorous confirmation of the relative importance of the precipitation variability differences among atmosphere-only models, we perform a PUP based on empirical orthogonal function (EOF) analysis of the standard deviations of precipitation across those models. This shows a very strong signal in the SPCZ and not elsewhere; the leading PUP, which explains greater than $60 \%$ of the variance using both the full precipitation signal as well as the synoptic-only precipitation signal, exhibits its strongest spatial loading in the SPCZ. Table 3 summarizes the quantitative grouping of models based on the ratio of precipitation standard deviation within the subtropical SPCZ in each model compared to TRMM, as well as the sign of the principal component of the first PUP using both the full precipitation signal and the synoptic-only precipitation signal. Those models that both exceed 0.8 for a standard deviation ratio and have a negative loading for the first PUP (consistent with higher precipitation standard deviations) using both signals are considered high-variability group (HVG) models. Those that meet none of the aforementioned criteria are considered low-variability group (LVG) models. The remaining models are considered intermediate-variability group (IVG) models.

The relevance of this precipitation variability to precipitation on daily time scales is shown in the precipitation histograms for TRMM, coupled models, and atmosphere-only models (Fig. 6). Those models in the HVG (mean error -0.16) tend to simulate histograms comparable to TRMM. Conversely, LVG histograms tend to disagree more with respect to TRMM (mean error - 0.43), especially INM-CM4 and NorESM1-M, which very noticeably diverge from the other model 

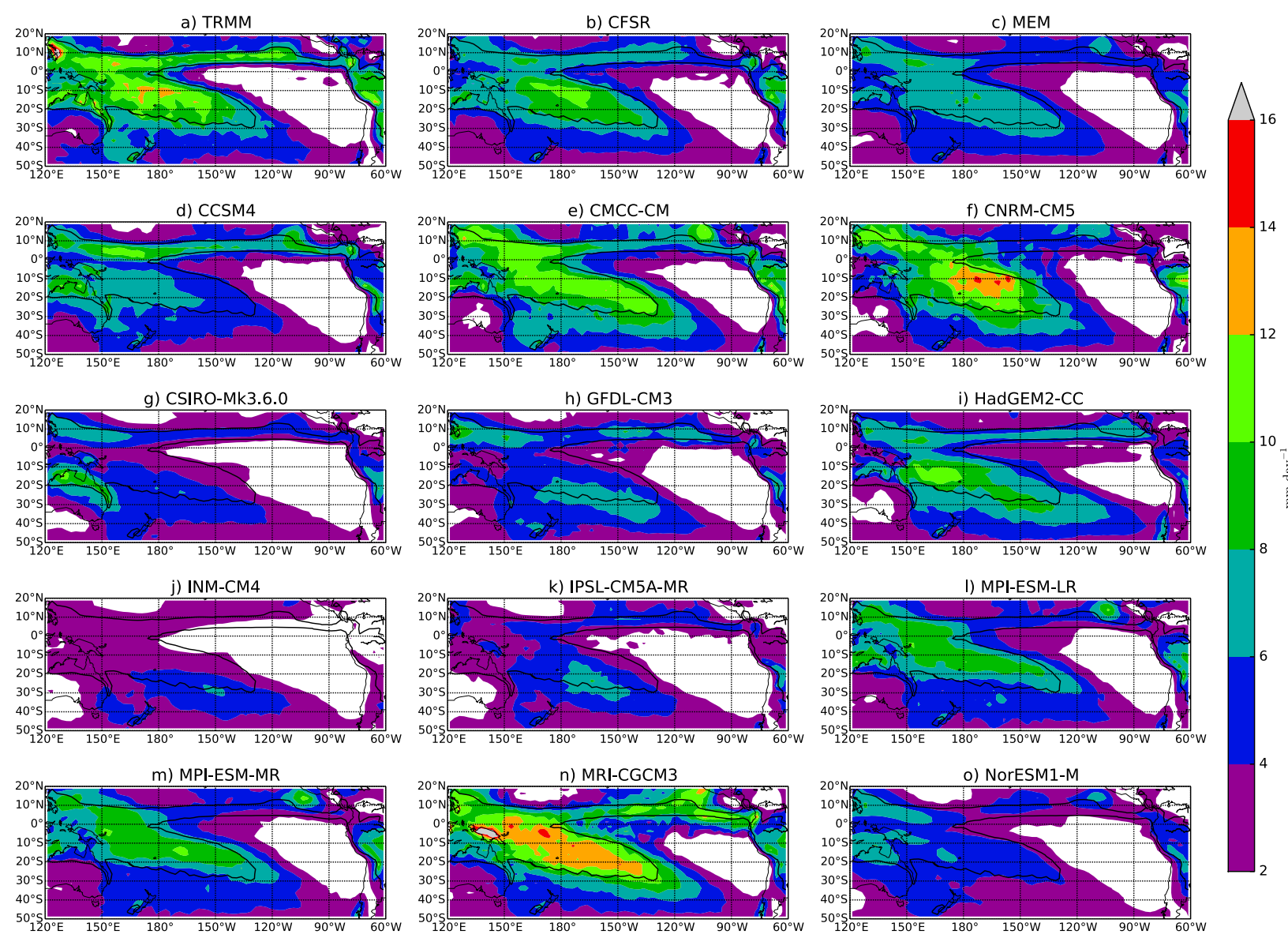

FIG. 5. As in Fig. 4, but for standard deviation of 14-day high-pass filtered precipitation.

histograms beyond $35-40 \mathrm{~mm} \mathrm{day}^{-1}$ regardless of coupling. A majority of the models simulate too much light precipitation at the expense of both heavy precipitation and dry days, which is a well-known bias in climate models, although somewhat alleviated in CMIP5 compared to CMIP3 (DeAngelis et al. 2013; Sillmann et al. 2013). Among coupled models, CMCC-CM and MRICGCM3 actually show positive errors; however, both CMCC-CM and MRI-CGCM3 simulate too low a climatological precipitation value (see Table 2) in the subtropical SPCZ (more than one standard deviation below the model mean). We further note that both models are capturing light precipitation accurately, underestimating precipitation in the range of $15-50 \mathrm{~mm} \mathrm{day}^{-1}$, and overestimating precipitation heavier than $50 \mathrm{~mm} \mathrm{day}^{-1}$. CNRMCM5 perhaps best illustrates the point that even with reasonable precipitation climatology and variability, a model may still display some subtle biases on the synoptic time scale; in addition to underestimating dry days and overestimating light precipitation, it underestimates precipitation in the range $15-50 \mathrm{~mm} \mathrm{day}^{-1}$ but performs well toward the tail of the distribution (high precipitation).
In the case of atmosphere-only models, four out of five HVG models now have large positive errors (mean error 0.63 ), with most of the error evident at precipitation values greater than $50 \mathrm{~mm} \mathrm{day}^{-1}$. The most extreme case of this is MRI-CGCM3 (error 1.53), the only model capable of simulating mean subtropical SPCZ precipitation greater than CFSR. Conversely, the LVG models show little alleviation of error (mean error 0.44) despite improved climatological representation of the SPCZ. Thus, it is not immediately obvious that atmosphereonly models are simulating more realistic histograms than coupled models-only five models show a decrease in error, and arguably only GFDL-CM3 shows notable improvement of those five. However, many models do show an increase in precipitation values between 15 and $50 \mathrm{~mm}_{\text {day }^{-1}}$, consistent with an increase in storms entering the subtropical SPCZ. This could be due to an alleviation of the storm graveyard position bias in coupled models, discussed further in section 4 .

We note that the class of convective parameterization scheme (e.g., closure on moisture convergence or buoyancy) has been shown to have an impact on the simulation 
TABLE 3. Grouping of models based on two criteria for proper simulation of precipitation variability using both the full precipitation record as well as a reconstructed synoptic precipitation signal. (a) The ratio of model precipitation standard deviation $(\sigma)$ to TRMM precipitation standard deviation in the subtropical SPCZ $\left(20^{\circ}-35^{\circ} \mathrm{S}, 135^{\circ}-165^{\circ} \mathrm{W}\right)$. Ratios that exceed the threshold value of 0.8 are shown in bold. (b) The principal component of the first principal uncertainty pattern (PUP) for model precipitation standard deviation. Negative PUP values are shown in bold. (c) Models that meet all criteria $(\sigma$ ratios $>0.8$ and $\mathrm{PC}<0$ ) belong to the high-variability group (HVG); models that meet none belong to the low-variability group $(\mathrm{LVG})$; the remaining models belong to the intermediate-variability group (IVG). Meeting any individual criterion for inclusion in the HVG group is denoted by boldface.

\begin{tabular}{|c|c|c|c|c|c|c|c|}
\hline Dataset & $\begin{array}{l}(\text { a) } \\
\sigma \text { ratio }\end{array}$ & $\sigma$ ratio (synoptic) & $\begin{array}{c}\text { (b) } \\
\text { PUP } 1 \text { PC }\end{array}$ & PUP 1 PC (synoptic) & $\begin{array}{c}\text { (c) } \\
\text { HVG }\end{array}$ & IVG & LVG \\
\hline CFSR & 1.023 & 0.9824 & - & - & & & \\
\hline CCSM4 & 0.706 & 0.674 & 0.326 & 0.078 & & & $\mathrm{X}$ \\
\hline CMCC-CM & 1.164 & 1.161 & -1.343 & -1.275 & $\mathrm{X}$ & & \\
\hline CNRM-CM5 & 1.182 & 1.177 & -0.746 & $-\mathbf{1 . 0 5 6}$ & $X$ & & \\
\hline CSIRO-Mk3.6.0 & 0.658 & 0.618 & 1.066 & 1.013 & & & $\mathrm{X}$ \\
\hline GFDL-CM3 & 0.854 & 0.840 & 0.753 & 0.644 & & $\mathrm{X}$ & \\
\hline HadGEM2-CC & 1.045 & 1.027 & -0.350 & -0.171 & $\mathrm{X}$ & & \\
\hline INM-CM4 & 0.754 & 0.659 & 1.410 & 1.558 & & & $\mathrm{X}$ \\
\hline IPSL-CM5A-MR & 0.777 & 0.762 & 1.145 & 1.058 & & & $\mathrm{X}$ \\
\hline MPI-ESM-LR & 0.843 & 0.794 & -0.629 & -0.319 & & $\mathrm{X}$ & \\
\hline MPI-ESM-MR & 0.868 & 0.818 & -0.792 & -0.441 & $\mathrm{X}$ & & \\
\hline MRI-CGCM3 & 1.340 & 1.334 & -1.651 & $-\mathbf{1 . 8 3 8}$ & $\mathrm{X}$ & & \\
\hline NorESM1-M & 0.618 & 0.562 & 0.810 & 0.749 & & & $\mathrm{X}$ \\
\hline
\end{tabular}

of tropical variability in climate models (e.g., the MJO; Slingo et al. 1996; Lin et al. 2006). However, no such dependence was found here for the SPCZ.

\section{b. Power spectra analyses}

An alternative way to establish how well models are simulating variability on synoptic time scales is through the use of power spectra analysis. A power spectra analysis of TOA OLR is calculated for both coupled (Fig. 7a) and atmosphere-only (Fig. 7b) models in the subtropical SPCZ. Consistent with observations and CFSR, the variability in both sets of models is significant between one and two weeks, with many models showing at least one distinct spectral peak in that range. In the case of the atmosphere-only models, many have too strong a magnitude for synoptic variability compared to CFSR, perhaps at the expense of power at other time scales (such as the MJO; see Hung et al. 2013). CNRMCM5 and GFDL-CM3 show less variability than the other models at synoptic time scales in the atmosphereonly experiment, with the former being notable since it is the only CMIP5 model capable of simulating an eastward-propagating $\mathrm{MJO}$ and displaying realistic MJO variability on the 30-70-day time scale (Hung et al. 2013). There is no obvious relationship between the TOA OLR power spectra magnitudes and the previous model groupings.

Figures $7 \mathrm{c}$ and $7 \mathrm{~d}$ show the results of a similar spectral analysis but using precipitation instead of TOA OLR. We note, however, that the correlation between the TRMM and CFSR power spectra is less than the correlation between the NOAA OLR product and CFSR
OLR, although this departure could be partly due to the difference in time series length between TRMM and CFSR. Again consistent with precipitation estimates and CFSR, the variability is significant between one and two weeks with at least one distinct peak. Although CFSR has a higher climatological precipitation value in the subtropical SPCZ than TRMM, CFSR precipitation variability has lower magnitude than TRMM. Despite the differences between precipitation estimates and reanalysis and consistent with the precipitation standard deviation results in section 3a, many coupled and atmosphere-only models are underestimating precipitation variability, particularly at time scales longer than 1 week. HVG models perform notably better than IVG and LVG models at matching TRMM variability magnitudes, although beyond two weeks all models are underestimating precipitation variability. Among the more interesting results here is INM-CM4, which performs poorly on time scales less than 7 days but then performs better than many LVG models on longer periods.

In summary, the results of spectral analysis are mixed; the variability of TOA OLR in these models, and hence clouds, is too high on synoptic time scales whereas the synoptic variability of precipitation is too low.

\section{Storm graveyard statistics}

Both the coupled model and atmosphere-only model precipitation histograms and TOA OLR/precipitation power spectra suggest a potential deficit of storm interactions in the subtropical SPCZ. Low precipitation variability on synoptic time scales could be explained in 

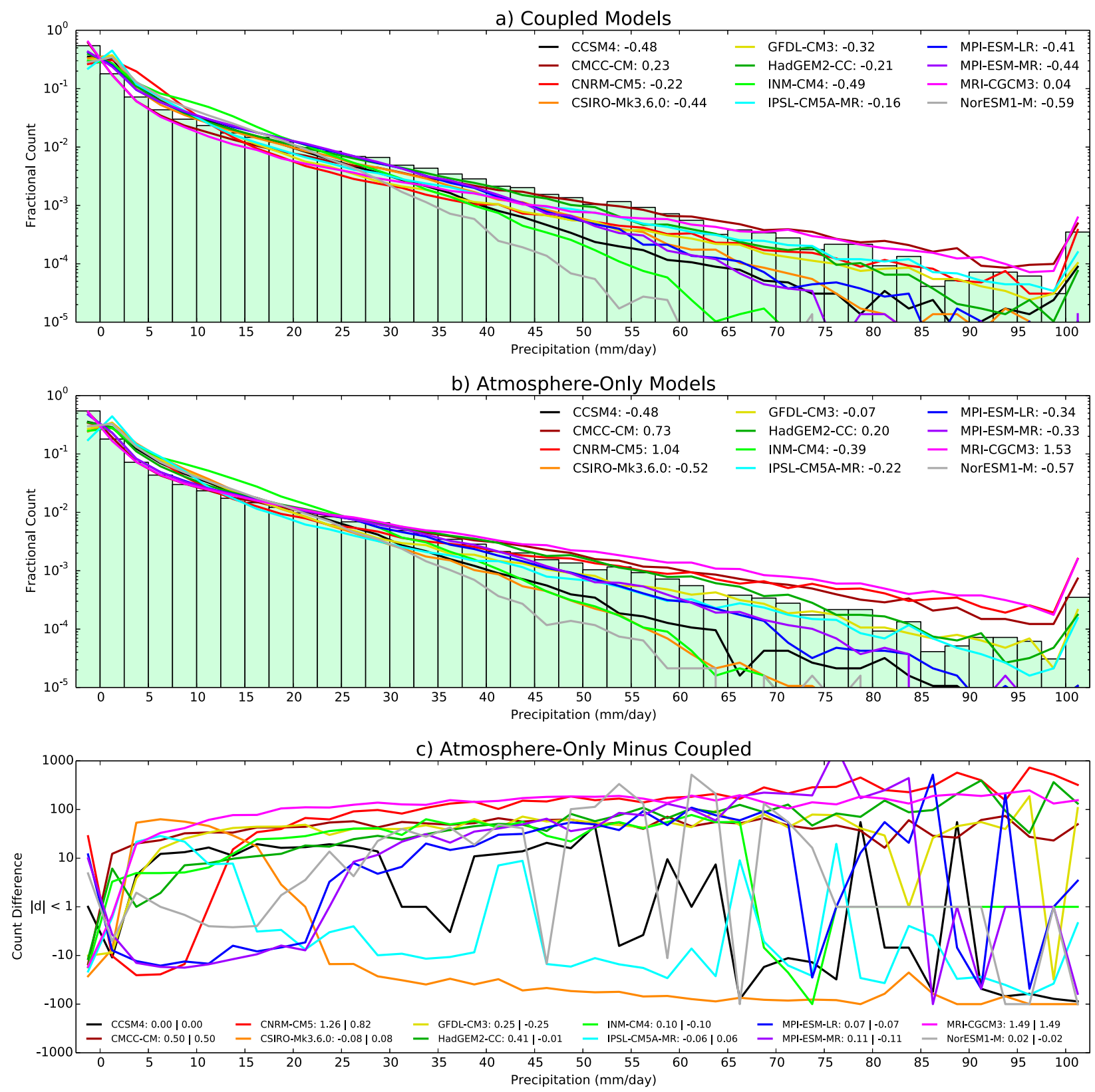

FIG. 6. Normalized, logarithmic DJF precipitation histograms in the region $20^{\circ}-35^{\circ} \mathrm{S}, 165^{\circ}-135^{\circ} \mathrm{W}$ from (a) coupled and (b) atmosphereonly models as well as their differences. The first bin measures $0-0.5 \mathrm{~mm} \mathrm{day}^{-1}$ counts, followed by $0.5-2.5 \mathrm{~mm} \mathrm{day}^{-1}$, with each subsequent bin having size $2.5 \mathrm{~mm}_{\text {day }}{ }^{-1}$ (e.g., $2.5-5.0 \mathrm{~mm}_{\text {day }}{ }^{-1}$ ). The final bin measures precipitation values exceeding $100 \mathrm{~mm} \mathrm{day}^{-1}$. (a) TRMM (green boxes) and coupled models (lines); error (see section 2 for details) shown in the legend for each model. (b) TRMM (green boxes) and atmosphere-only models (lines); error from TRMM shown in the legend for each model. (c) Difference between atmosphere-only and coupled model histograms for each model (lines); difference and increase/decrease in error, respectively, between atmosphere-only and coupled histograms shown in the legend for each model.

part by a decreased frequency of synoptic disturbances propagating into the subtropical SPCZ, or by differing characteristics of these disturbances (e.g., lower rainfall rates). Previous work (Widlansky et al. 2011; Matthews 2012) outlined the importance of the storm graveyard region in explaining both the diagonal tilt and variability of rainfall in the SPCZ; thus, we explore how the storm graveyard is simulated in CMIP5 models, as errors could have not only a profound impact on both the synoptic variability of the region but also previously highlighted climatological biases (see Fig. 2). 

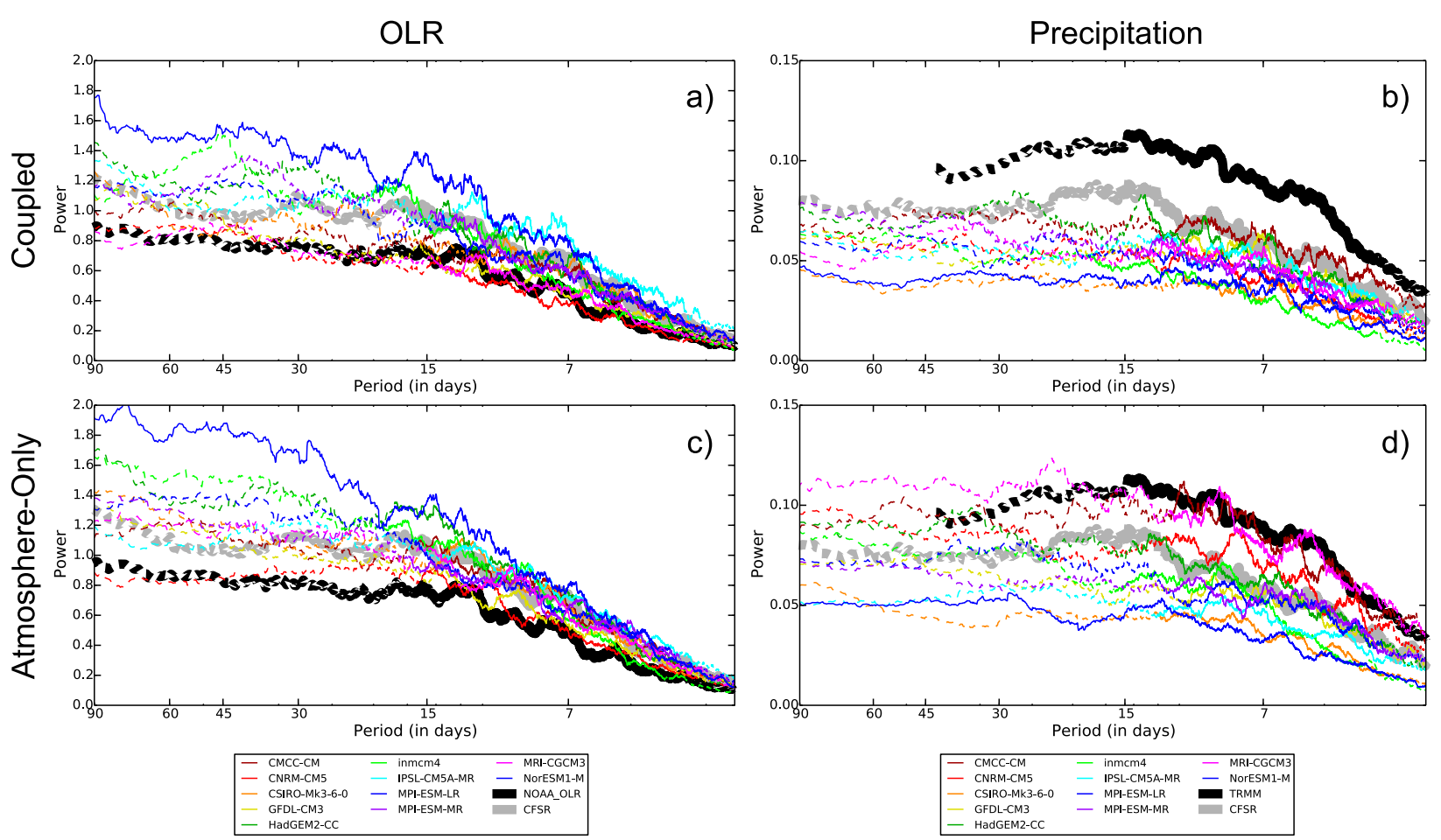

FIG. 7. Normalized power spectra in (top) coupled and (bottom) atmosphere-only models. (left) For OLR spectra, models are compared to CFSR and a NOAA OLR observational dataset. (right) For precipitation spectra, models are compared to CFSR and TRMM precipitation estimates. Solid (dashed) line indicates variability above (below) the significance threshold (explained in section 2).

Figure 8 shows the zonal stretching deformation (i.e., $\left.\partial \bar{U}_{250} / \partial x\right)$ metric previously used to demarcate the boundaries of the storm graveyard, although we simplify by showing the zonal mean across $35^{\circ}-20^{\circ} \mathrm{S}$. The region in which ZSD is negative in the central Pacific denotes the storm graveyard. Clearly, coupled models show a wide range $\left(\sim 180^{\circ} \pm 30^{\circ}\right)$ of western boundaries, whereas atmosphere-only models have a much more condensed range $\left(\sim 180^{\circ} \pm 10^{\circ}\right)$. The eastern boundaries show less improvement moving from coupled to atmosphere-only; in fact, the MEM shows a consistent eastward bias in the eastern edge of the graveyard consistent with models simulating increased precipitation farther east than climatologically observed. Looking strictly at the MEM for both cases, it is apparent that the coupled model storm graveyards are weaker in magnitude by nearly half and have minimum ZSD values farther east $\left(125^{\circ} \mathrm{W}\right)$ than observed $\left(135^{\circ} \mathrm{W}\right)$. The atmosphere-only graveyards show a notably reduced bias both in terms of magnitude and position of minimum ZSD, which can also be seen in the difference plots between the two experiments. These improvements are perhaps unsurprising considering that regions of negative ZSD are closely tied to atmospheric circulation, which will be more similar to observations when models are forced with climatological SSTs instead of allowing SST errors to perturb the atmospheric circulation.
A two-dimensional view of storm graveyard biases is presented for coupled models in Fig. 9. In the model ensemble mean, it is again evident that there is an eastward displacement in the graveyard, although a slight northward bias is also apparent. Despite a slight eastward bias in the MEM, there is a large spread in the longitude of the ZSD minimum among models. This is also evident in the larger graveyard structure; IPSL-CM5AMR has perhaps the largest westward bias, whereas MRICGCM3 has a very pronounced eastward bias. The spread in magnitude of ZSD minima is also noteworthy. However, this does not obviously correlate well with the previously established model variability groupings. Although other than CNRM-CM5 the HVG models simulate graveyard with reasonably strong magnitudes compared to the IVG and LVG models, IPSL-CM5A-MR (an LVG model) simulates a graveyard qualitatively similar to climatology.

Figure 10 is similar to Fig. 9, but showing atmosphereonly model results in lieu of coupled models. Much of the model biases in terms of both magnitude and position are alleviated, although the longitudinal spread in ZSD minima is of comparable magnitude. While it is not obvious if there are any positional differences between HVG and LVG model storm graveyards, there does appear to be a tendency for HVG models to simulate 
a) Coupled Model ZSD: $20^{\circ} \mathrm{S}-35^{\circ} \mathrm{S}$ Mean

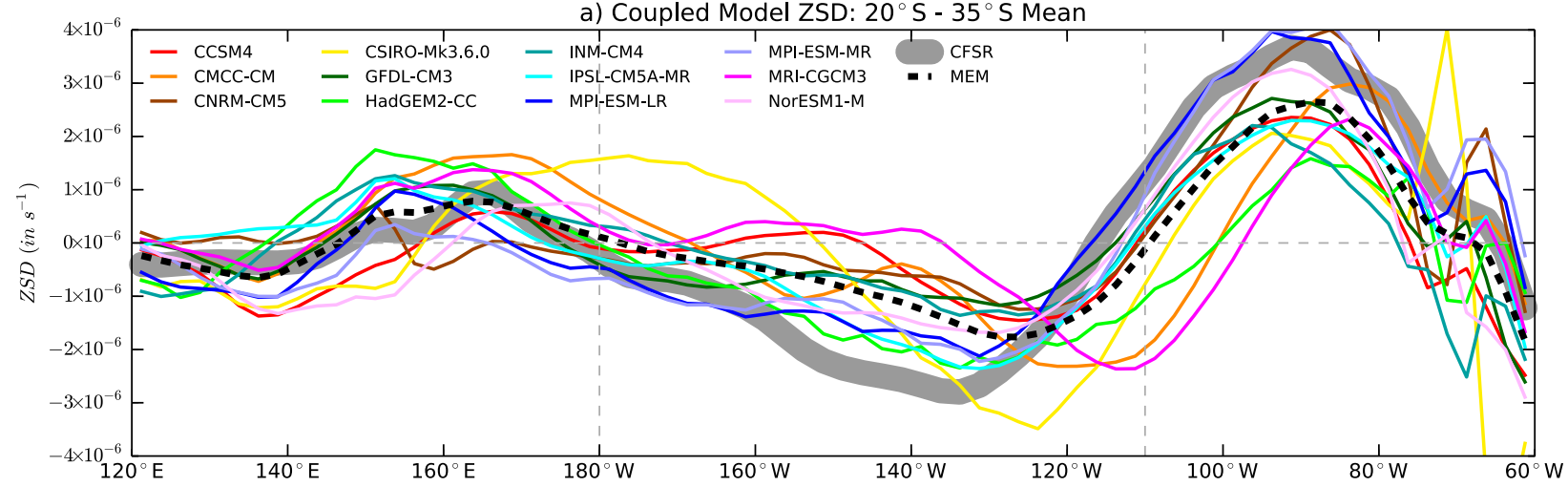

b) Atmosphere-Only Model ZSD: $20^{\circ} \mathrm{S}-35^{\circ} \mathrm{S}$ Mean

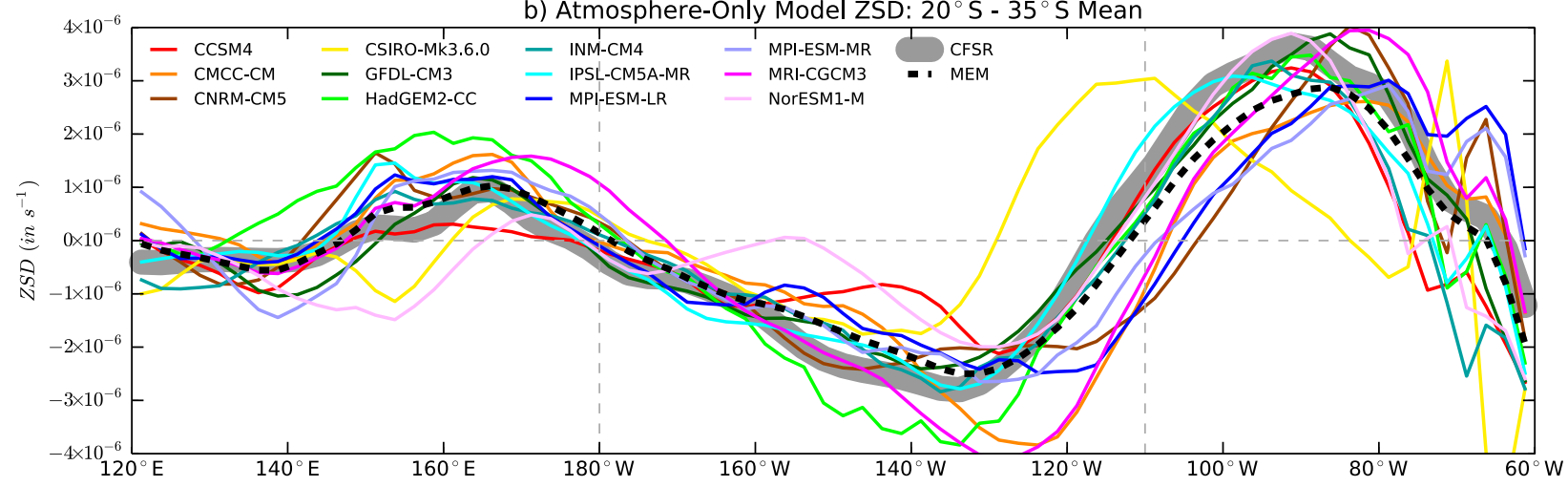

C) Atmosphere-Only - Coupled ZSD: $20^{\circ} \mathrm{S}-35^{\circ} \mathrm{S}$ Mean

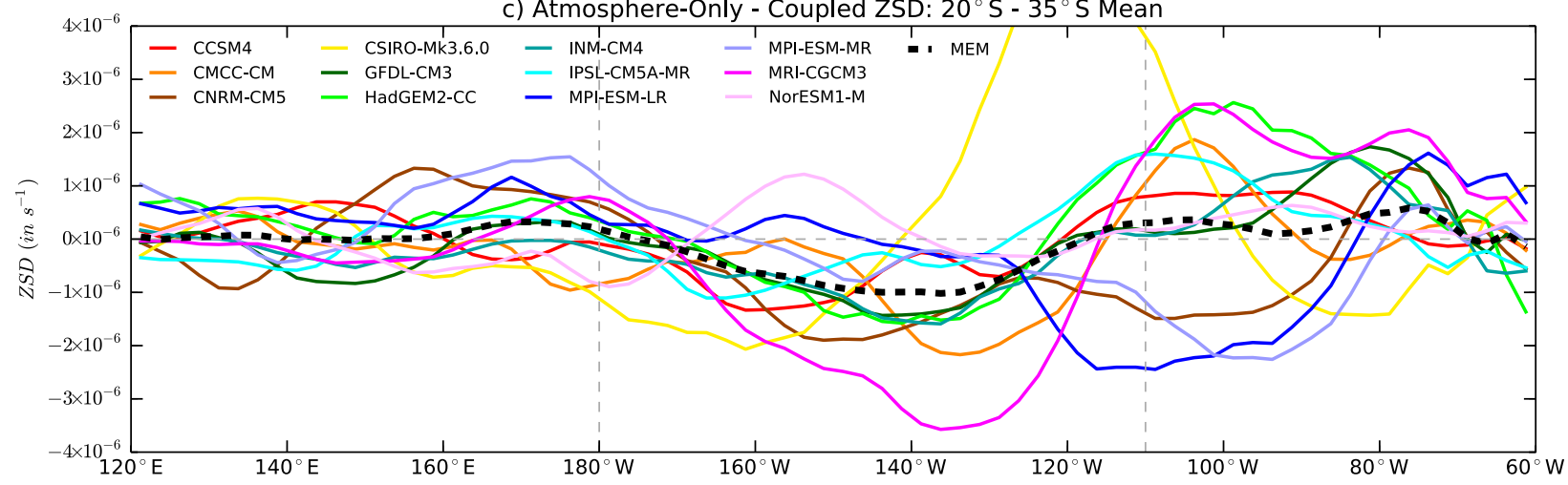

FIG. 8. Meridional average $\left(20^{\circ}-35^{\circ} \mathrm{S}\right)$ of zonal stretching deformation (ZSD) in CFSR and models across the South Pacific $\left(120^{\circ} \mathrm{E}-\right.$ $60^{\circ} \mathrm{W}$ ), for (a) coupled and (b) atmosphere-only models, and (c) the difference between atmosphere-only and coupled models. MEM denotes the model ensemble mean in each panel.

graveyards with stronger magnitudes of ZSD than the LVG models. In particular, MRI-CGCM3 and CMCC$\mathrm{CM}$, models that both show close-to-observed precipitation variability, have particularly strong ZSD minima-more than $30 \%$ stronger in magnitude. The correlation between subtropical SPCZ synoptic precipitation standard deviation and the magnitude of storm graveyard ZSD minimum in the atmosphere-only models is significant at the $5 \%$ level based on a two-tailed $t$ test with 10 degrees of freedom. This suggests that there is a possibility for increased storm interaction in models with stronger graveyards, which would in turn lead to higher precipitation variability.

\section{Composite analysis of synoptic disturbances interacting with the SPCZ}

Because of the variety of storm graveyard solutions among coupled and atmosphere-only models, we explore differences between the models and observational/reanalysis 

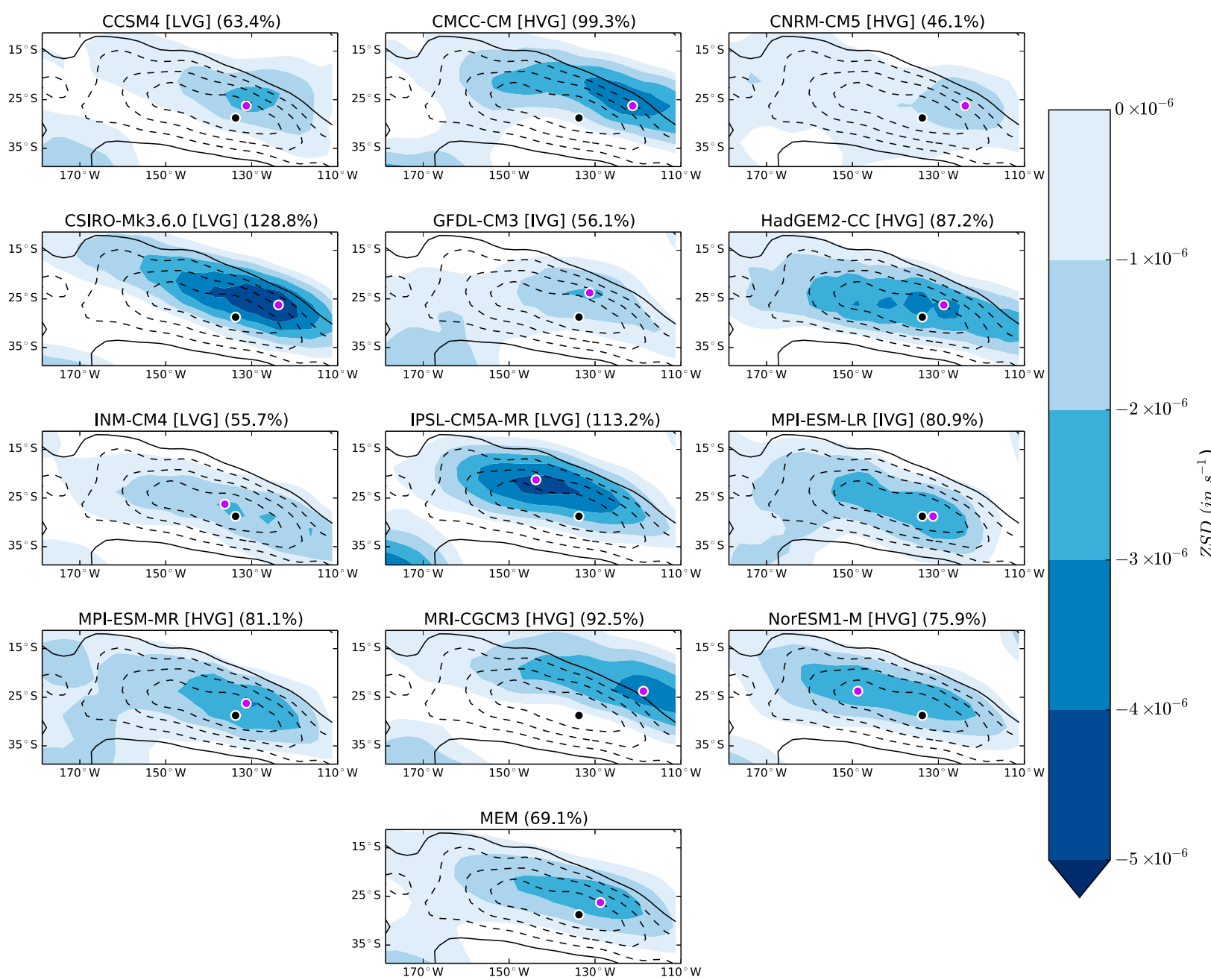

$\times 10^{-6}$

FIG. 9. Coupled model negative zonal stretching deformation at $250 \mathrm{hPa}$ (blue shading, $\mathrm{s}^{-1}$ ) as compared to CFSR negative ZSD (black contours) at the same level in the storm graveyard region, as well as the coupled model ensemble mean (MEM). The locations of the CFSR (black dot) and individual model or MEM (purple dot) ZSD minimum are shown for reference. The relative strength of the minimum value of ZSD in each model compared to CFSR is shown in parentheses after each model name.

products in the propagation of vorticity anomalies as they enter the SPCZ using composite analysis. Figure 11 shows the results of the composite of vorticity anomalies at $250 \mathrm{hPa}$ (see section 2 for further information) using CFSR as well as the MEM results for both coupled and atmosphere-only models. CFSR shows a propagation of the vorticity anomalies toward the northeast, from approximately $35^{\circ} \mathrm{S}, 140^{\circ} \mathrm{W}$ on day -2 to $30^{\circ} \mathrm{S}, 135^{\circ} \mathrm{W}$ on day 0 . The atmosphere-only and coupled models show similar motion. During the same period, the precipitation anomalies in the eastern SPCZ in all data sources are located along a distinct axis oriented from northwest to southeast, with wet anomalies northeast of the axis and dry anomalies southeast. There is also a wet precipitation anomaly southwest of the dry anomaly in some cases, confirming the path of the wave train as northeastward or east-northeastward. During day 1 and day 2 , both the vorticity and precipitation anomalies decay. While the vorticity anomalies drift toward the east, the precipitation anomalies drift toward the northwest, with faster motion in CFSR compared to the MEMs. In analysis of individual models (not shown), only a small subset of the coupled (CSIRO-Mk3.6.0, GFDL-CM3, and MPI-ESM-LR/MR) and atmosphere-only (CMCCCM, MPI-ESM-MR, and NorESM1-M) models show precipitation anomalies that drift toward the northwest with similar speed to CFSR; the others tend to show relatively stationary anomalies as seen in the MEMs. Propagation biases could be due in part to the influence of equatorial Rossby waves in the region, which are not well simulated in all models (G. Kiladis 2014, personal communication); thus, the composite analysis may not be 

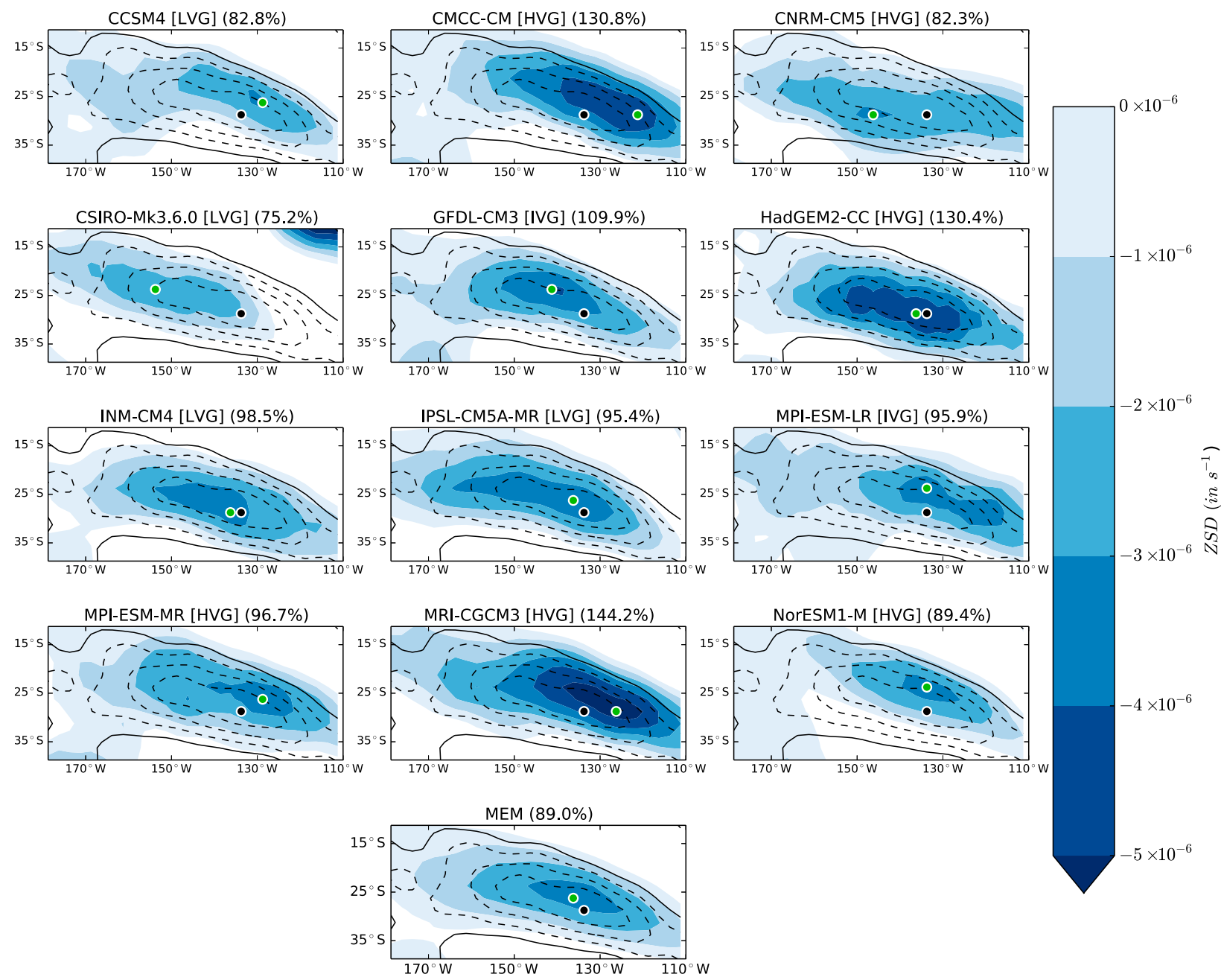

FIG. 10. As in Fig. 9, but using data from the atmosphere-only models and their MEM. The locations of the individual model or MEM ZSD minima are now denoted by a green dot.

solely picking up interactions between the SPCZ and midlatitude synoptic disturbances. Other than simulating precipitation anomalies without the observed northwestward drift following a storm interaction event, these composite results do not suggest that either MEM is substantially biased in interactions between synoptic disturbances and the SPCZ.

To elucidate whether individual models exhibit a zonal bias to the trajectories of vorticity anomalies approaching the SPCZ, a vorticity backtracking algorithm is used to recover the linear trajectory and speed of individual interactions in reanalysis data compared to coupled and atmosphere-only model output (Figs. 12 and 13, respectively). There is no notable bias in modeled storm trajectory in terms of MEM results, with atmosphere-only and coupled models simulating tracks consistent with CFSR. However, a spread in approach angle of approximately $\pm 10^{\circ}$ among individual coupled and atmosphere-only models does exist. There is a correlation between ZSD minimum values and storm approach angle in the atmosphere-only model results (significant at the $5 \%$ level), but the correlation sign is inconsistent with the expectation that a stronger graveyard would result in weaker eastward advection and increased equatorward diversion toward the westerly wind duct. Additionally, there is no such significant correlation in the coupled models. Thus, we conclude that these variations in storm trajectory are not physically meaningful. On the other hand, consistent with a weaker graveyard in models, both the coupled and atmosphere-only MEM speed of the storms is 0.8 and $0.6 \mathrm{~m} \mathrm{~s}^{-1}$ faster than CFSR, respectively. However, storm speeds calculated for individual models do not show any strong correlation with the ZSD minimum values (neither is significant at the $10 \%$ level). No other significant correlations arose with storm trajectory and 

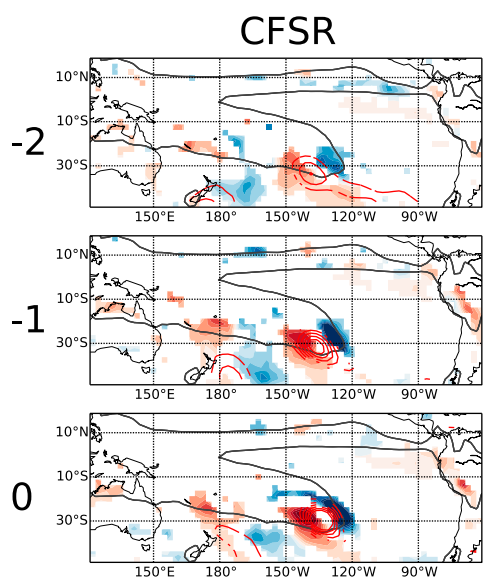

1

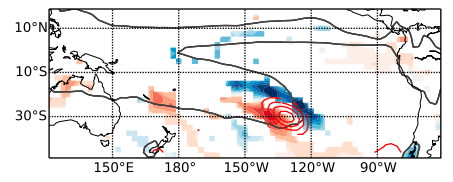

2

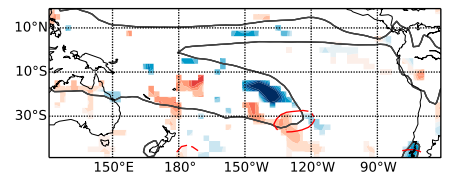

Atmos-Only
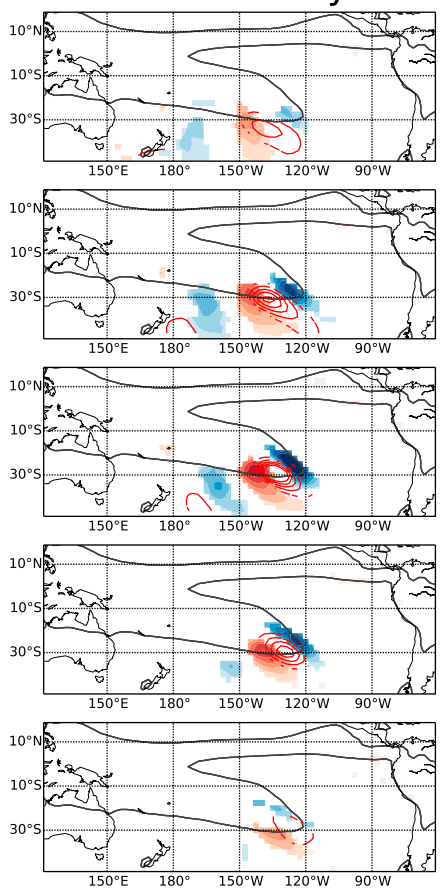

Coupled
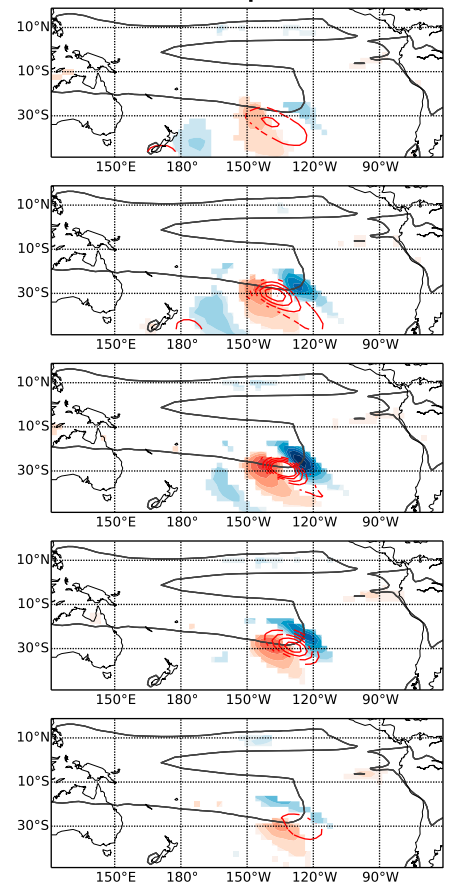

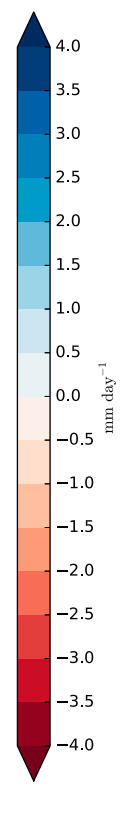

FIG. 11. Composite analysis using $250-\mathrm{hPa}$ vorticity in the region $27.5^{\circ}-30^{\circ} \mathrm{S}, 140^{\circ}-127.5^{\circ} \mathrm{W}$ : (left) CFSR, (middle) atmosphere-only MEM, and (right) coupled MEM. Each row denotes the days before or after the low vorticity event (i.e., -2 is 2 days before, etc.). Shown in each panel are precipitation anomalies (shading, $\mathrm{mm}^{-1} \mathrm{y}^{-1}$ ), negative vorticity anomalies (red contours, starting at $0 \mathrm{~s}^{-1}$; each subsequent contour is $-1 \times 10^{-5} \mathrm{~s}^{-1}$ ), and the data source's climatological $4 \mathrm{~mm}$ day $^{-1}$ precipitation (black contour). For CFSR, anomalies are only shown if they are greater than $99 \%$ of randomly generated composite differences. For the coupled and atmosphere-only MEMs, anomalies are shown if 8 or more of the models agree on both the sign and significance (same as for CFSR) of the anomaly at any given location.

speed among individual coupled and atmosphere-only models. Thus, if the correlation between mean synoptic precipitation variability and storm graveyard ZSD minima has a physical basis, it is unlikely related to obvious differences in SPCZ-storm interaction among models.

Because of the difference in precipitation anomaly propagation, it is worth examining the development of specific humidity anomalies at lower levels and midlevels throughout the storm interactions. Like Fig. 11, Fig. 14 shows the results of the static composite analysis, but vorticity has been replaced with lower-level $(850 \mathrm{hPa})$ and midlevel $(500 \mathrm{hPa})$ specific humidity. In the CFSR results, there is a tendency for the midlevel positive moisture anomalies to appear more prominently leading up to day 0 ; conversely, the dry anomalies behind the storm are evident at both levels. Also worth noting are the precipitation anomalies in the storm track southwest of the SPCZ, as they are associated primarily with a lowlevel moisture anomaly. Because the SPCZ environment is already favorable for convection (e.g., warm SSTs, conditional instability), the lower level is already close to saturation; thus, the main impact that the interacting storm has is encouraging deeper convection, resulting in the midlevel moisture anomaly observed. There is no evidence of a temporal offset between precipitation and moisture leading up to the storm interaction, although there does appear to be a tendency for the moisture anomaly to drift farther north than the precipitation anomaly during days 1 and 2 .

In terms of the models, both the coupled and atmosphere-only models manifest a midlevel moisture anomaly in the SPCZ, an equivalent barotropic dry anomaly southwest, and a low-level moisture anomaly associated with a separate storm farther southwest. To better understand if individual models are showing a similar drift in specific humidity, a representative subset of atmosphere-only models is shown in Fig. 15. There appear to be four distinct moisture-precipitation relationships in the models. The most similar model to CFSR in terms of the magnitude and propagation of the primary moisture anomaly within the SPCZ is CCSM4, although it does not show a particularly strong secondary moisture anomaly farther southwest. MPI-ESM-MR also performs well, although it shows a more barotropic moisture anomaly in the SPCZ, less obvious propagation signatures, and a strong barotropic moist anomaly 
a) CFSR (50): $49^{\circ}, 2.8 \mathrm{~m} / \mathrm{s}$

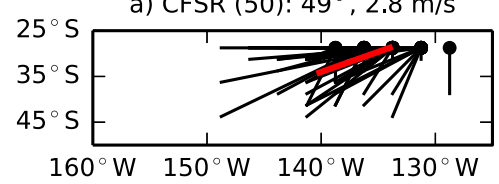

c) CCSM4 (89): $52^{\circ}, 3.7 \mathrm{~m} / \mathrm{s}$
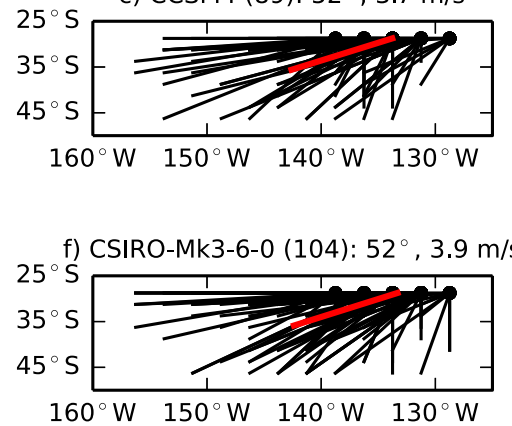

i) INM-CM4 (101): $46^{\circ}, 3.2 \mathrm{~m} / \mathrm{s}$

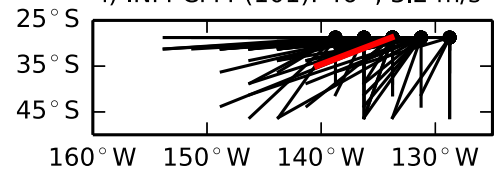

I) MPI-ESM-MR (87): $43^{\circ}, 3.3 \mathrm{~m} / \mathrm{s}$

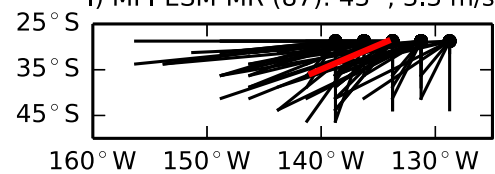

d) CMCC-CM (82): $49^{\circ}, 3.5 \mathrm{~m} / \mathrm{s}$

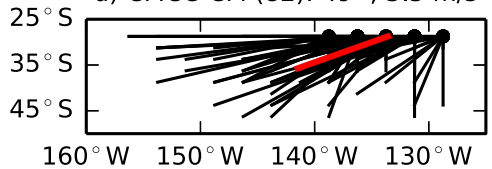

g) GFDL-CM3 (111): $45^{\circ}, 3.5 \mathrm{~m} / \mathrm{s}$
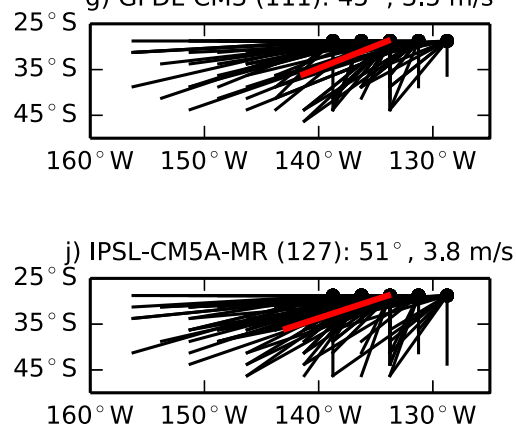

m) MRI-CGCM3 (74): $49^{\circ}, 3.7 \mathrm{~m} / \mathrm{s}$

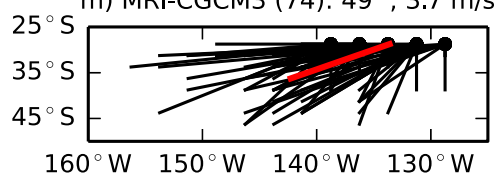

b) $\operatorname{MEM}(1123): 49^{\circ}, 3.6 \mathrm{~m} / \mathrm{s}$

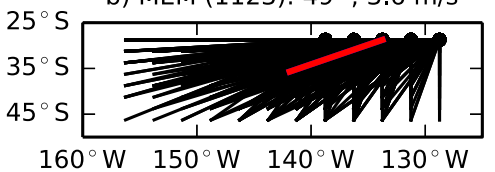

e) CNRM-CM5 (81): $47^{\circ}, 3.8 \mathrm{~m} / \mathrm{s}$

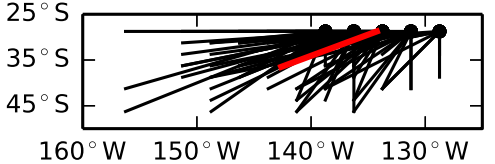

h) HadGEM2-CC (90): $63^{\circ}, 3.4 \mathrm{~m} / \mathrm{s}$

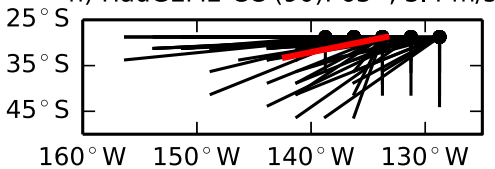

k) MPI-ESM-LR (94): $43^{\circ}, 3.8 \mathrm{~m} / \mathrm{s}$

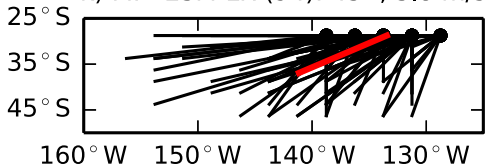

n) NorESM1-M (83): $52^{\circ}, 3.7 \mathrm{~m} / \mathrm{s}$

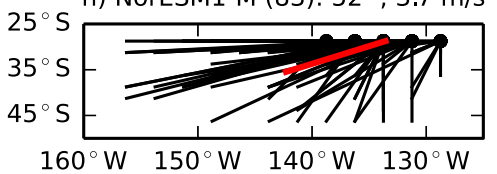

FIG. 12. Linear trajectories of storms entering the SPCZ included in the composites shown in Fig. 10 for (a) CFSR, (b) the coupled model ensemble mean, and (c)-(n) individual coupled models. Listed after the data source name are the number of storms plotted (in parentheses) as well as the angle and speed of the red trajectory, which connects the mean starting and ending position for each data source. For angles, $0^{\circ}$ is toward due north, $90^{\circ}$ is toward due east, etc.

farther southwest. In the case of MRI-CGCM3, results compare with MPI-ESM-MR, although the midlevel moisture anomaly in the SPCZ is more stationary. Finally, INM-CM4 lacks a particularly strong moisture anomaly associated with its precipitation enhancement in the SPCZ and manifests much stronger dry and wet barotropic anomalies toward the southwest. Thus, the lack of motion to both the precipitation and moisture anomalies as seen in the MEM for coupled and atmosphere-only models during and after storm interactions is representative of many, though not all, of the individual model results.

\section{Summary and conclusions}

We have evaluated the ability of current-generation coupled climate and atmosphere-only models to simulate synoptic time scale variability in the SPCZ. The standard deviation of precipitation across the South Pacific varies substantially between models, particularly within the $4 \mathrm{~mm} \mathrm{day}^{-1}$ contour of the climatological SPCZ. Extreme examples among atmosphere-only models include INM-CM4, which shows weak variability (4-6 mm day ${ }^{-1}$ ), and MRI-CGCM3, which shows very strong variability $\left(12-16 \mathrm{~mm} \mathrm{day}^{-1}\right)$. Observed values from TRMM and reanalysis values from CFSR are near the model upper extreme (10-14 $\left.\mathrm{mm} \mathrm{day}^{-1}\right)$. The ratio of each model's precipitation standard deviation to TRMM does not change noticeably when limiting standard deviation to the synoptic time scale (defined here as less than 14 days).

The tendency for low precipitation variability in the SPCZ is consistent with CMIP5 model biases in precipitation shown previously (Sillmann et al. 2013); that is, the coupled models tend to overestimate moderate precipitation at the expense of both light and heavy 


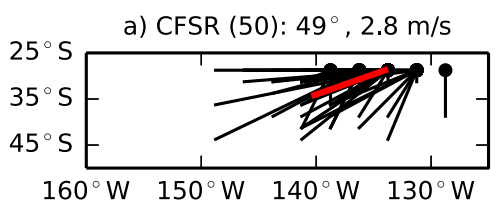

c) $\operatorname{CCSM} 4(68): 40^{\circ}, 3.5 \mathrm{~m} / \mathrm{s}$

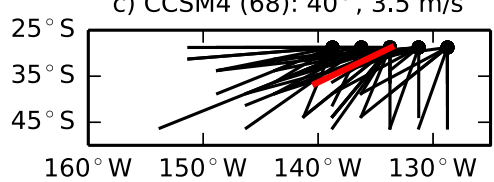

f) CSIRO-Mk3-6-0 (59): $45^{\circ}, 3.3 \mathrm{~m} / \mathrm{s}$

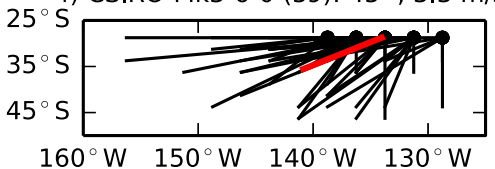

i) INM-CM4 (62): $51^{\circ}, 2.9 \mathrm{~m} / \mathrm{s}$

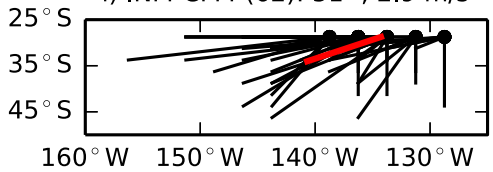

I) MPI-ESM-MR (64): $47^{\circ}, 3.3 \mathrm{~m} / \mathrm{s}$

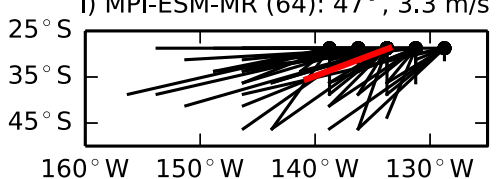

d) $\mathrm{CMCC}-\mathrm{CM}(57): 46^{\circ}, 3.6 \mathrm{~m} / \mathrm{s}$

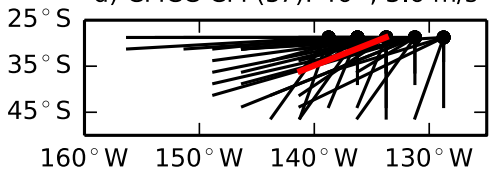

g) GFDL-CM3 (48): $53^{\circ}, 3.6 \mathrm{~m} / \mathrm{s}$
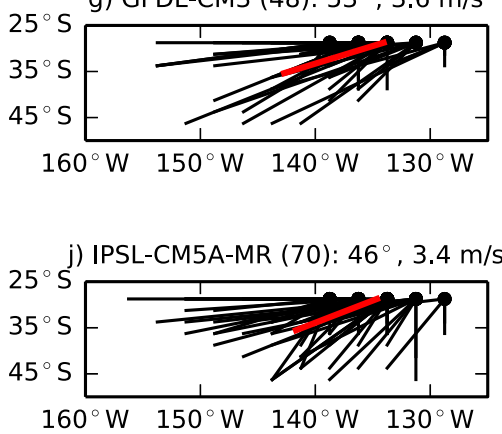

m) MRI-CGCM3 (79): $54^{\circ}, 3.4 \mathrm{~m} / \mathrm{s}$

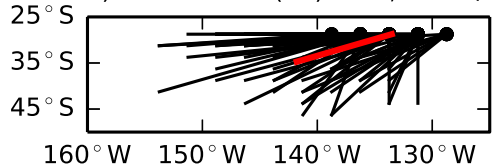

b) $\operatorname{MEM}(741): 48^{\circ}, 3.4 \mathrm{~m} / \mathrm{s}$

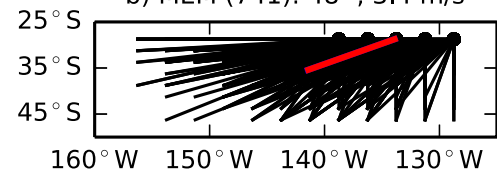

e) CNRM-CM5 (70): $51^{\circ}, 3.4 \mathrm{~m} / \mathrm{s}$

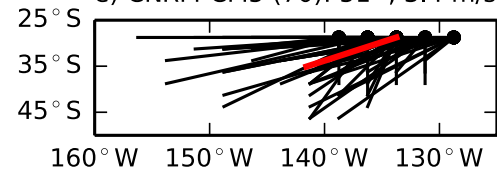

h) HadGEM2-A (57): $58^{\circ}, 3.7 \mathrm{~m} / \mathrm{s}$

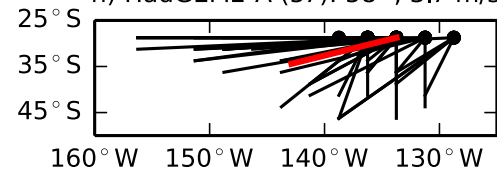

k) MPI-ESM-LR (57): $43^{\circ}, 3.4 \mathrm{~m} / \mathrm{s}$

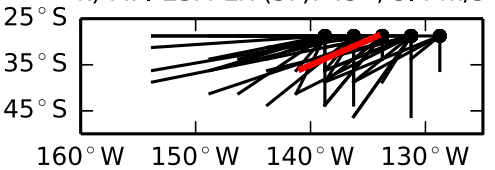

n) NorESM1-M (50): $49^{\circ}, 3.8 \mathrm{~m} / \mathrm{s}$

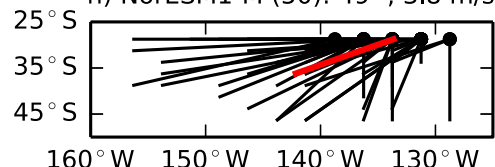

FIG. 13. As in Fig. 12, but for atmosphere-only models.

precipitation, which is evident in the precipitation histograms. However, the overestimate in moderate precipitation is only partially eliminated in the atmosphere-only models, suggesting that biases in simulated SST in the South Pacific are not the sole reason for this type of error. Model precipitation power spectra are consistent with the histogram results, although OLR appears to vary too strongly. These results point toward problems in model cloud and precipitation parameterizations that still need to be addressed.

Prior work highlighted the importance of storm interactions in generating SPCZ convection (Widlansky et al. 2011; Matthews 2012); thus, it is plausible that intermodel differences in the frequency and characteristics of storm interactions in the subtropical SPCZ may account for differences in model precipitation variability. As a first attempt at examining these differences, we performed an analysis of the storm graveyard in both coupled and atmosphere-only models. Whereas considerable spread is evident across both the coupled and atmosphere-only models in terms of the magnitude and position of the storm graveyard, the latter show more consistency in the location of the western boundary of the feature. Whereas the coupled MEM graveyard is both weaker and further northeast than observed, both of these biases are alleviated in the atmosphere-only MEM. A significant correlation between graveyard intensity and precipitation variability is identified in the atmosphere-only models, consistent with the expectation that increased storm interactions lead to simulation of greater precipitation variability.

The static composite analysis based on upper-level vorticity within the storm graveyard region suggests no obvious bias in the storm trajectories as they approach the SPCZ. However, the models do not show as strong a propagation of precipitation anomalies toward the northwest into the tropical SPCZ following the interaction. To probe the storm interactions further, a vorticity backtracking algorithm was employed. Results of the backtracking indicate no notable bias in the simulated storm trajectories but a positive propagation speed bias stronger in the coupled models. Although 

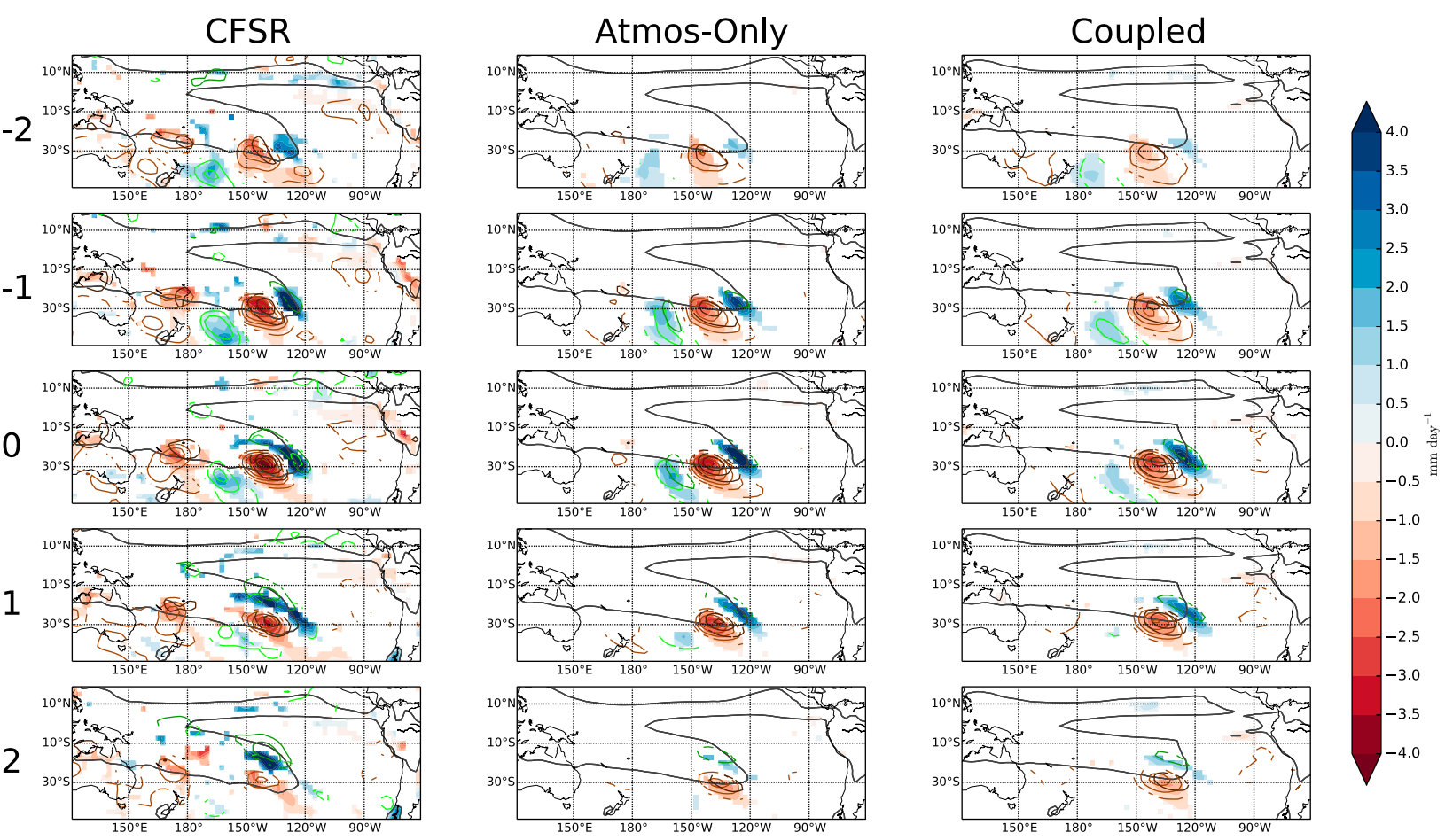

FIG. 14. As in Fig. 11, but replacing vorticity anomalies with moisture anomalies at two levels. Positive moisture anomalies are contoured at $850 \mathrm{hPa}$ (light green) and $500 \mathrm{hPa}$ (dark green) every $0.25 \mathrm{~g} \mathrm{~kg}^{-1}$; similarly, negative moisture anomalies are contoured at $850 \mathrm{hPa}$ (light brown) and $500 \mathrm{hPa}$ (dark brown) every $0.25 \mathrm{~g} \mathrm{~kg}^{-1}$. The same significance criteria are used for moisture that were used for precipitation and vorticity in Fig. 11.

these results are consistent with expectations considering a weaker simulated storm graveyard, the correlation between graveyard intensity and either the approach angle or propagation speed in the individual models is not strong. Finally, lower-level and midlevel moisture anomalies during the period of the static composite analysis were considered, as they may reveal more information about the differences in behavior between observed and modeled precipitation anomaly drift. Reanalysis moisture anomalies within the SPCZ are stronger at the midlevels, consistent with storm interactions triggering deeper convection; in the models, this is generally true, but there is a greater tendency for lowerlevel anomalies as well. As with the precipitation anomalies, these moisture anomalies tend to be more stationary in the models than in CFSR. There is broad agreement on a barotropic dry anomaly southwest of the SPCZ during the interaction, consistent with the observed wave train pattern, and more limited agreement on a low-level secondary anomaly farther west. The results show no evidence of a temporal lag between moisture increases and precipitation onset on the daily time scale.

Overall, we conclude that current-generation coupled and atmosphere-only models show significant biases in precipitation variability on synoptic time scales, although it remains unclear how strong a role differences in storm interactions play in generating these biases. Because results of the composite analysis were relatively consistent (i.e., it was not a question of whether storms interacted in an individual model, but how), it is plausible that differences in model parameterizations (specifically convective parameterizations) may explain the differences in precipitation variability, as suggested in section 3. It is also worth noting that recent work by $\mathrm{Li}$ et al. (2014) suggests that the exclusion of the radiative effects of snow within clouds in CMIP3 and CMIP5 models leads to a positive zonal wind bias in the vicinity of the storm graveyard; this model error is consistent with the northeastward bias in the position of the ZSD minimum of the coupled MEM as well as the positive rainfall bias on the northern side of the storm graveyard and warrants more study of the dynamic and thermodynamic properties of the subtropical SPCZ. As a starting point, a process-based examination of the differences in both dynamic and thermodynamic characteristics of the synoptic disturbances among models, and how they compare to reanalysis products, is planned; previous processbased diagnostics have proven to be critically important (e.g., Widlansky et al. 2011; Matthews 2012; van der Wiel et al. 2015). 

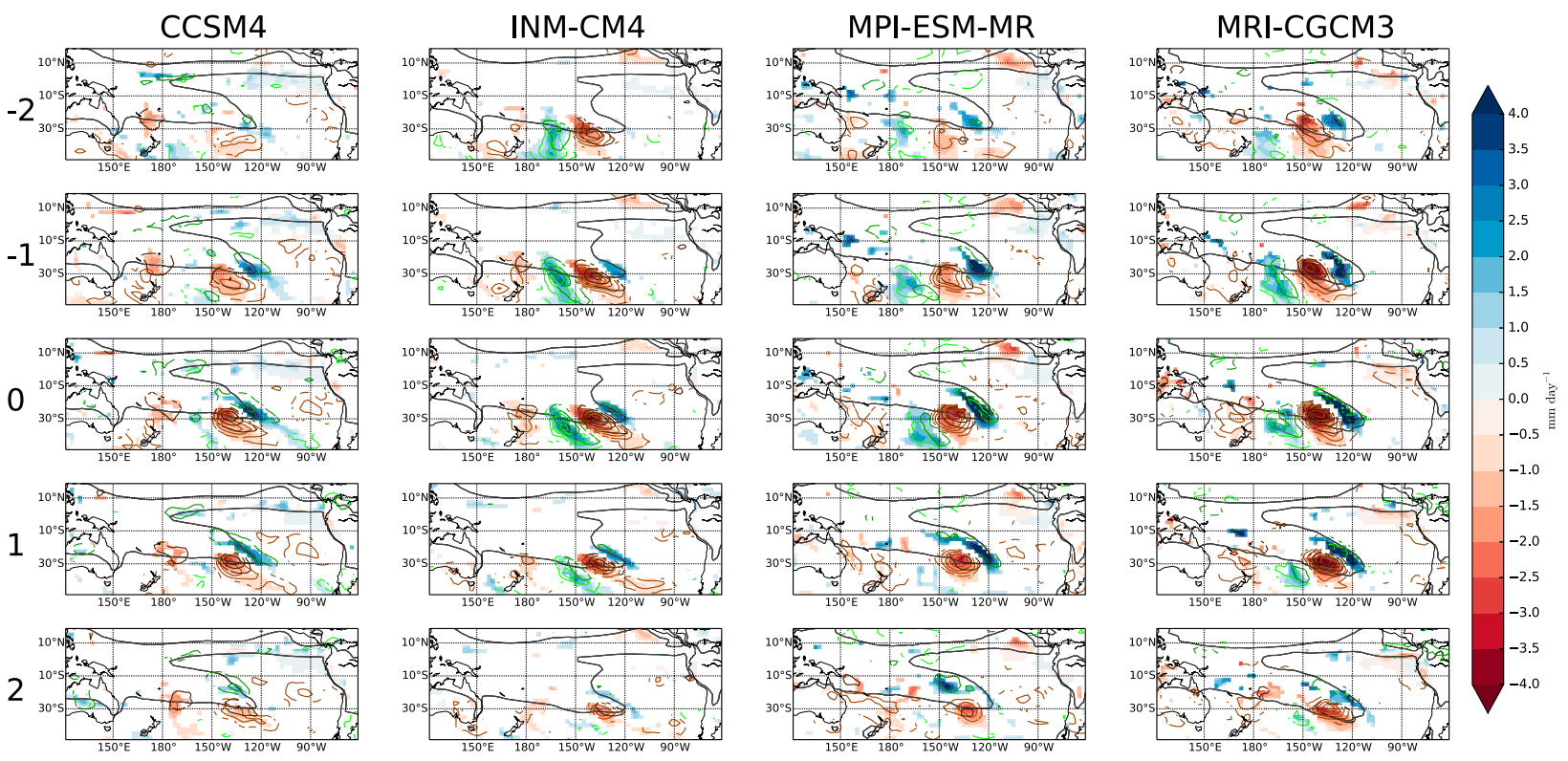

FIG. 15. As in Fig. 14, but showing four individual atmosphere-only models. Significance criteria for showing precipitation/moisture anomalies are the same as used for CFSR in Figs. 11 and 14.

Given the significance of the SPCZ as a locus of extratropical-tropical interaction, we suggest field campaigns that could improve understanding of the dynamic and thermodynamic environment in which these interactions take place. A characterization of the vertical structure of circulation and moisture over the course of interaction events would be especially useful. Furthermore, campaigns could include an assessment of trace constituents such as $\mathrm{CO}_{2}$ or anthropogenic constituents, since the SPCZ appears to provide a preferential pathway along which transport to high latitudes occurs. For future model improvements, we provide the following checklist of parameters that must be well simulated in in a model to improve the representation of the SPCZ: 1) correct SST gradients across the South Pacific, 2) an accumulation zone for synoptic waves, and 3) an eastern boundary between moist convection and dry subsidence. Modeling studies that allow for careful perturbation of any combination of these parameters would be useful to elucidate SPCZ sensitivity.

Considering that the models simulate storm interactions with some consistency leads us to posit the following regarding SPCZ simulation in CMIP5: the simulated position of the subtropical portion of the SPCZ is less biased than the equatorial and tropical portions, which are strongly tied to the influence of erroneous SSTs in the equatorial region. Careful examination of the axis of maximum precipitation throughout the SPCZ in TRMM suggests an increased tilt of the subtropical SPCZ relative to the tropical SPCZ, consistent with the recent statistical work of Haffke and Magnusdottir (2013). In some coupled models (e.g., HadGEM2-CC) the change in tilt between the western and eastern SPCZ is drastic, but this bias is largely because the western, more tropical portion of the SPCZ is overly zonal. As a result, it is perhaps necessary to treat the equatorial/tropical SPCZ and subtropical SPCZ as separate features when undertaking multimodel analyses of SPCZ bias.

Another direction for future work is the effect that a well-simulated MJO has on the synoptic variability of the SPCZ. However, given that the MJO is simulated with varying success in current-generation models, it may not yet be feasible to examine this linkage. Future studies of the simulated SPCZ should nonetheless consider the MJO and associated biases in synoptic precipitation variability, although such interactions are likely focused in the tropics with only remote impacts on precipitation in the diagonal region.

Acknowledgments. This work was funded by National Science Foundation Grant NSF-AGS-1312865. We acknowledge the World Climate Research Programme's Working Group on Coupled Modelling, which is responsible for CMIP, and we thank the climate modeling groups (listed in Table 1 of this paper) for producing and making available their model output. For CMIP the U.S. Department of Energy's Program for Climate Model Diagnosis and Intercomparison provides coordinating support and led development of software infrastructure in partnership with the Global Organization for Earth System Science Portals. CMAP precipitation data were provided by the NOAA/OAR/ESRL PSD, Boulder, 
Colorado, USA, from their Web site at http:/www.esrl. noaa.gov/psd/. CFSR output was obtained from the Computation Information Systems Laboratory (CISL) Research Data Archive at http://rda.ucar.edu/datasets/ds093.1/. We thank Rosana Nieto-Ferreira, George Kiladis, and two anonymous reviewers for their helpful comments on this manuscript. We also thank Anthony DeAngelis for assistance in downloading and regridding the CMIP5 model output and valuable histogram discussions.

\section{REFERENCES}

Anderson, B. T., B. R. Lintner, B. Langenbruner, J. D. Neelin, E. Hawkins, and J. Sykus, 2015: Sensitivity of terrestrial precipitation to the structural evolution of sea surface temperatures. Geophys. Res. Lett., doi:10.1002/2014GL062593, in press.

Ashfaq, M., C. B. Skinner, and N. S. Diffenbaugh, 2011: Influence of SST biases on future climate change projections. Climate Dyn., 36, 1303-1319, doi:10.1007/s00382-010-0875-2.

Australian Bureau of Meteorology and CSIRO, 2011a: Regional Overview. Vol. 1, Climate Change in the Pacific: Scientific Assessment and New Research, BOM-CSIRO, 257 pp.

_ 2011b: Regional Overview. Vol 2, Climate Change in the Pacific: Scientific Assessment and New Research, BOMCSIRO, $273 \mathrm{pp}$.

Bellucci, A., S. Gualdi, and A. Navarra, 2010: The double-ITCZ syndrome in coupled general circulation models: The role of large-scale vertical circulation regimes. J. Climate, 23, 11271145, doi:10.1175/2009JCLI3002.1.

Borlace, S., A. Santoso, W. Cai, and M. Collins, 2014: Extreme swings of the South Pacific convergence zone and the different types of El Niño events. Geophys. Res. Lett., 41, 4695-4703, doi:10.1002/2014GL060551.

Brown, J. R., S. B. Power, F. P. Delage, R. A. Colman, A. F. Moise, and B. F. Murphy, 2011: Evaluation of the South Pacific convergence zone in IPCC AR4 climate model simulations of the twentieth century. J. Climate, 24, 1565-1582, doi:10.1175/ 2010JCLI3942.1.

_ A. F. Moise, and R. A. Colman, 2013: The South Pacific convergence zone in CMIP5 simulations of historical and future climate. Climate Dyn., 41, 2179-2197, doi:10.1007/s00382-012-1591-x.

Cai, W., and Coauthors, 2012: More extreme swings of the South Pacific convergence zone due to greenhouse warming. Nature, 488, 365-369, doi:10.1038/nature11358.

DeAngelis, A. M., A. J. Broccoli, and S. G. Decker, 2013: A comparison of CMIP3 simulations of precipitation over North America with observations: Daily statistics and circulation features accompanying extreme events. J. Climate, 26, 32093230, doi:10.1175/JCLI-D-12-00374.1

de Szoeke, S. P., and S.-P. Xie, 2008: The tropical eastern Pacific seasonal cycle: Assessment of errors and mechanisms in IPCC AR4 coupled ocean-atmosphere general circulation models. J. Climate, 21, 2573-2590, doi:10.1175/2007JCLI1975.1.

Folland, C. K., J. A. Renwick, M. J. Salinger, and A. B. Mullan, 2002: Relative influences of the interdecadal Pacific oscillation and ENSO on the South Pacific convergence zone. Geophys. Res. Lett., 29, 1643, doi:10.1029/2001GL014201.

Ganachaud, A., and Coauthors, 2007: Southwest Pacific Ocean Circulation and Climate Experiment (SPICE)—Part I. Scientific background. International CLIVAR Publ. Series, No. 111, NOAA/OAR Special Rep., NOAA/OAR/PMEL, 37 pp.
— and Coauthors, 2014: The Southwest Pacific Ocean Circulation and Climate Experiment (SPICE). J. Geophys. Res. Oceans, 119, 7660-7686, doi:10.1002/2013JC009678.

Haffke, C., and G. Magnusdottir, 2013: The South Pacific Convergence Zone in three decades of satellite images. J. Geophys. Res. Atmos., 118, 10 839-10 849, doi:10.1002/jgrd.50838.

Hung, M.-P., J.-L. Lin, W. Wang, D. Kim, T. Shinoda, and S. J. Weaver, 2013: MJO and convectively coupled equatorial waves simulated by CMIP5 climate models. J. Climate, 26, 6185-6214, doi:10.1175/JCLI-D-12-00541.1.

Kiladis, G. N., and K. M. Weickmann, 1997: Horizontal structure and seasonality of large-scale circulations associated with submonthly tropical convection. Mon. Wea. Rev., 125, 1997-2013, doi:10.1175/1520-0493(1997)125<1997:HSASOL>2.0.CO;2.

Kummerow, C., and Coauthors, 2000: The status of the Tropical Rainfall Measuring Mission (TRMM) after two years in orbit. J. Appl. Meteor., 39, 1965-1982, doi:10.1175/ 1520-0450(2001)040<1965:TSOTTR > 2.0.CO;2.

Li, J.-L. F., W.-L. Lee, D. E. Waliser, J. D. Neelin, J. P. Stachnik, and T. Lee, 2014: Cloud-precipitation-radiation-dynamics interaction in global climate models: A snow and radiation interaction sensitivity experiment. J. Geophys. Res. Atmos., 119, 3809-3824, doi:10.1002/2013JD021038.

Liebmann, B., and C. A. Smith, 1996: Description of a complete (interpolated) OLR dataset. Bull. Amer. Meteor. Soc., 77, 1275-1277.

Lin, J.-L., 2007: The double-ITCZ problem in IPCC AR4 coupled GCMs: Ocean-atmosphere feedback analysis. J. Climate, 20, 4497-4525, doi:10.1175/JCLI4272.1.

, and Coauthors, 2006: Tropical intraseasonal variability in 14 IPCC AR4 climate models. Part I: Convective signals. J. Climate, 19, 2665-2690, doi:10.1175/JCLI3735.1.

Matthews, A. J., 2012: A multiscale framework for the origin and variability of the South Pacific convergence zone. Quart. J. Roy. Meteor. Soc., 138, 1165-1178, doi:10.1002/qj.1870.

— B. J. Hoskins, J. M. Slingo, and M. Blackburn, 1996: Development of convection along the SPCZ within a MaddenJulian oscillation. Quart. J. Roy. Meteor. Soc., 122, 669-688, doi:10.1002/qj.49712253106.

Meehl, G. A., C. Covey, T. Delworth, M. Latif, B. McAvaney, J. F. B. Mitchell, R. J. Stouffer, and K. E. Taylor, 2007: The WCRP CMIP3 multimodel dataset: A new era in climate change research. Bull. Amer. Meteor. Soc., 88, 1383-1394, doi: 10.1175/BAMS-88-9-1383.

Murphy, B. F., S. B. Power, and S. McGree, 2014: The varied impacts of El Niño-Southern Oscillation on Pacific island climates. J. Climate, 27, 4015-4036, doi:10.1175/JCLI-D-13-00130.1.

Niznik, M. J., and B. R. Lintner, 2013: Circulation, moisture, and precipitation relationships along the South Pacific convergence zone in reanalyses and CMIP5 models. J. Climate, 26, 10 174-10192, doi:10.1175/JCLI-D-13-00263.1.

Saha, S., and Coauthors, 2010: The NCEP Climate Forecast System Reanalysis. Bull. Amer. Meteor. Soc., 91, 1015-1057, doi:10.1175/ 2010BAMS3001.1.

Sillmann, J., V. V. Kharin, F. W. Zwiers, X. Zhang, and D. Bronaugh, 2013: Climate extremes indices in the CMIP5 multimodel ensemble: Part 1. Model evaluation in the present climate. J. Geophys. Res. Atmos., 118, 1716-1733, doi:10.1002/jgrd.50203.

Slingo, J. M., and Coauthors, 1996: Intraseasonal oscillations in 15 atmospheric general circulation models: Results from an AMIP diagnostic subproject. Climate Dyn., 12, 325-358, doi:10.1007/ BF00231106

Streten, N. A., 1973: Some characteristics of satellite-observed bands of persistent cloudiness over the Southern Hemisphere. Mon. 
Wea. Rev., 101, 486-495, doi:10.1175/1520-0493(1973)101<0486: $\mathrm{SCOSBO}>2.3 . \mathrm{CO} ; 2$.

Taylor, K. E., R. J. Stouffer, and G. A. Meehl, 2012: An overview of CMIP5 and the experiment design. Bull. Amer. Meteor. Soc., 93, 485-498, doi:10.1175/BAMS-D-11-00094.1.

Trenberth, K. E., 1976: Spatial and temporal variations of the Southern Oscillation. Quart. J. Roy. Meteor. Soc., 102, 639653, doi:10.1002/qj.49710243310.

van der Wiel, K., A. J. Matthews, D. P. Stevens, and M. M. Joshi, 2015: A dynamical framework for the origin of the diagonal South Pacific and South Atlantic convergence zones. Quart. J. Roy. Meteor. Soc., doi:10.1002/qj.2508, in press.

Vannière, B., E. Guilyardi, T. Toniazzo, G. Madec, and S. Woolnough, 2014: A systematic approach to identify the sources of tropical SST errors in coupled models using the adjustment of initialised experiments. Climate Dyn., 43, 2261-2282, doi:10.1007/ s00382-014-2051-6.

Vincent, D. G., 1994: The South Pacific convergence zone (SPCZ): A Review. Mon. Wea. Rev., 122, 1949-1970, doi:10.1175/ 1520-0493(1994)122<1949:TSPCZA > 2.0.CO;2.
Vincent, E. M., M. Lengaigne, C. E. Menkes, N. C. Jourdain, P. Marchesiello, and G. Madec, 2011: Interannual variability of the South Pacific convergence zone and implications for tropical cyclone genesis. Climate Dyn., 36, 1881-1896, doi:10.1007/ s00382-009-0716-3.

Widlansky, M. J., P. J. Webster, and C. D. Hoyos, 2011: On the location and orientation of the South Pacific convergence zone. Climate Dyn., 36, 561-578, doi:10.1007/s00382-010-0871-6.

—, A. Timmermann, K. Stein, S. McGregor, N. Schneider, M. H. England, M. Lengaigne, and W. Cai, 2013: Changes in South Pacific rainfall bands in a warming climate. Nat. Climate Change, 3, 417-423, doi:10.1038/nclimate1726.

, S. McGregor, M. F. Stuecker, and W. Cai, 2014: An interhemispheric tropical sea level seesaw due to El Niño taimasa. J. Climate, 27, 1070-1081, doi:10.1175/JCLI-D-13-00276.1.

Xie, P., and P. A. Arkin, 1997: Global precipitation: A 17-year monthly analysis based on gauge observations, satellite estimates, and numerical model outputs. Bull. Amer. Meteor. Soc., 78, 2539-2558, doi:10.1175/1520-0477(1997)078<2539:GPAYMA>2.0.CO;2.

Zhang, C., 2001: Double ITCZs. J. Geophys. Res., 106, 11785 11 792, doi:10.1029/2001JD900046. 